\title{
Spatial and Temporal Variability in the Precipitation Concentration in the Upper Reaches of the Hongshui River Basin, Southwestern China
}

\author{
Ya Huang $\mathbb{D}$, ${ }^{1,2}$ Hao Wang $\mathbb{D}^{2},{ }^{2}$ Weihua Xiao $\mathbb{D},{ }^{2}$ Li-hua Chen $\left(\mathbb{D},{ }^{1}\right.$ Deng-hua Yan $(\mathbb{D})^{2}$ \\ Yu-yan Zhou, ${ }^{2}$ Da-chuan Jiang $\mathbb{D}^{2},{ }^{2}$ and Ming-zhi Yang $\mathbb{D}^{2}$ \\ ${ }^{1}$ College of Civil Engineering and Architecture, Guangxi University, Nanning, Guangxi 530004, China \\ ${ }^{2}$ State Key Laboratory of Simulation and Regulation of Water Cycle in River Catchment, China Institute of Water Resources and \\ Hydropower Research, Beijing 100038, China \\ Correspondence should be addressed to Weihua Xiao; xwsen998@163.com
}

Received 1 September 2017; Revised 12 January 2018; Accepted 31 January 2018; Published 11 March 2018

Academic Editor: Luis Gimeno

Copyright (c) 2018 Ya Huang et al. This is an open access article distributed under the Creative Commons Attribution License, which permits unrestricted use, distribution, and reproduction in any medium, provided the original work is properly cited.

\begin{abstract}
The statistical characteristics of precipitation play important roles not only in flood and drought risk assessments but also in water resource management. This paper implements a statistical analysis to study the spatial and temporal variability in precipitation in the upper reaches of the Hongshui River basin (UHRB), southwestern China, by analysing time series of daily precipitation from 18 weather stations during the period of 1959 to 2015. To detect precipitation concentrations and the associated patterns, three indices, the precipitation concentration index (PCI), precipitation concentration degree (PCD), and precipitation concentration period (PCP), were used. The relationships between the precipitation concentration indices (PCI, PCD, and PCP) and geographic variables (latitude, longitude, and elevation), large-scale atmospheric circulation indices, and summer monsoon indices were investigated to identify specific dependencies and spatial patterns in the precipitation distribution and concentration. The results show that high PCI values were mainly observed in the northeastern portion of the basin, whereas low PCI values were mainly detected in the southwest. The Mann-Kendall test results demonstrate that the majority of the UHRB is characterized by nonsignificant trends in the PCI, PCD, and PCP from 1959 to 2015. The PCP results reveal that rainfall in the UHRB mainly occurs in summer months, and the rainy season arrives earlier in the eastern UHRB than in the western UHRB. Additionally, the PCD results indicate that the rainfall in the western UHRB is more dispersed throughout the year than that in the eastern UHRB. Compared with other geographical factors, longitude is the most important variable that governs the spatial distribution and variations in annual precipitation and the precipitation concentration indices. Due to a combination of topography, the Indian subtropical high, and monsoon weakening, precipitation may be more concentrated in one period, especially in the eastern part of the basin, which increases the risk of drought.
\end{abstract}

\section{Introduction}

As temperatures increase, the amount of water vapour in the atmosphere increases and the temporal and spatial distributions of precipitation change, resulting in large precipitation differences in different regions of the world [1-3]. Precipitation patterns are expected to spatially and temporally change around the world due to an increase in the water-holding capacity of the air, which in turn results in the acceleration of the hydrological cycle and affects the spatiotemporal characteristics of precipitation [4-6]. Both global [7] and regional $[8,9]$ precipitation characteristics have changed due to the influence of climate change and intensified human activities. A significantly decreasing number of rain days and significantly increasing precipitation intensities have been identified in many places around the world, such as in China $[8,10]$, the United States [11, 12], Spain [13], Iraq [14], and Siberia [15].

Therefore, extreme climatic and weather events have garnered considerable attention from public, government, 
and academic communities around the world [12, 16-19]. In recent years, numerous studies have shown that the frequencies of extreme precipitation events and associated disasters have significantly increased. Thus, more attention has focused on the intensity, frequency, and spatiotemporal variation of extreme precipitation. Moreover, analyses of daily precipitation distributions and temporal precipitation patterns are important in climate research. Changes in precipitation intensities, amounts, and patterns can cause extreme events, such as droughts and floods, to occur more frequently [20, 21]. These extreme events may influence erosion, agriculture, water supplies, storm water drainage, energy production, and so on [22]. A small change in mean precipitation may result in a relatively large increase in the probability of extreme precipitation [23]. In some cases, extremes have occurred despite decreases or stable trends in mean precipitation [5]. Therefore, information regarding the changing patterns of precipitation is important for the accurate assessment of water resources, drought and flood control, efficient water management, and the understanding of climate change [24].

Recently, three different indices, including the precipitation concentration index $(\mathrm{PCI})$, precipitation concentration degree (PCD), and precipitation concentration period (PCP), were developed to describe different aspects of the magnitude and period of precipitation. Martin-Vide [13], a meteorologist from Spain, defined the PCI. The index can estimate the differences between the percentages of precipitation associated with different precipitation days. Specifically, the PCI represents the contribution of days of heavy precipitation to the total amount of precipitation over a certain period (usually 1 year). Since Martin-Vide initially proposed the PCI, it has been used to detect or monitor the temporal heterogeneity in the precipitation distributions of many regions around the world [20,25-29]. Zhang and Qian [30] used the vector analysis principle to define two indices, the PCD and PCP, to analyse the temporal characteristics of precipitation. Considering their scientific and practical merits, the PCD and PCP have been used in many studies to analyse the properties and spatial and temporal characteristics of precipitation at the regional and subregional scales in recent years $[20,25,26,28$, 29]. Various indicators have distinct advantages; therefore, to scientifically evaluate the spatial and temporal variations of precipitation, it is necessary to analyse these indices at the same time.

In this study, the upper Hongshui River basin (UHRB) was selected as the study area. Zhang et al. [29] used the PCI to analyse changes in precipitation in the Pearl River basin, where the UHRB is located. His research showed that the southwest and northeast parts of the Pearl River basin are characterized by low and decreasing PCI values, and the PCI values in the northwest and south parts of the basin are high and increasing. Significant increases in the PCI after 1990 were detected in the West River, lower North River, and upper Beipan River basins. However, to the best of our knowledge, there has been no other comprehensive study of precipitation concentration changes, either spatial or temporal changes, in the UHRB. The basin has not been adequately investigated in previous studies. Thus, a detailed analysis of the statistical characteristics of temporal and spatial variations in daily precipitation across the UHRB could enhance the understanding of the statistical characteristics of precipitation extremes, improve water resource management, and reduce climate-induced flood risks. This study investigates the spatial distribution of the PCI, PCD, and PCP based on daily precipitation data and identifies and quantifies PCI, PCD, and PCP trends and the associated spatial and temporal patterns across the UHRB from 1959 to 2015. The relationships among geographic variables (such as latitude, longitude, and elevation), large-scale atmospheric circulation indices, summer monsoon indices, the annual precipitation distribution, and concentration indices are investigated. The results of this study provide important information for water management and environmental problem solving by policymakers and stakeholders.

\section{Study Region and Data Sources}

2.1. Study Region. The Hongshui River is the main stream of the Xijiang River in the Pearl River basin, which has abundant water power resources and is one of the twelve bases for hydropower construction in China. The UHRB, which is located in the southwest part of China (between $102^{\circ} 14^{\prime} \mathrm{E}-107^{\circ} 32^{\prime} \mathrm{E}$ and $23^{\circ} 11^{\prime} \mathrm{N}-27^{\circ} 01^{\prime} \mathrm{N}$, Figure 1 ), is on the southeast side of the Yunnan-Guizhou Plateau. It has an area of $98500 \mathrm{~km}^{2}$ and accounts for $71 \%$ of the area of the Hongshui River basin. Moreover, the exploitable hydropower in the UHRB accounts for more than $80 \%$ of that in the entire basin. To the southeast is the South China Sea, and the Bay of Bengal lies to the southwest of the study area. Because the region is easily affected by the East Asian monsoon and the South Asian monsoon, the precipitation amount in summer is large, and the flood disasters often occur. The basin has a subtropical monsoon climate that is mainly affected by the East Asian monsoon, and the average annual precipitation in the basin varies between 760 and $1860 \mathrm{~mm}$. Approximately $88 \%$ of the total precipitation in the UHRB occurs during the flooding season, which extends from April to October. The terrain of the UHRB is complex, with a plateau, hills, and plains, and the elevation gradually decreases from the northwest plateau to the southeast plain.

2.2. Data Processing, Quality Control, and Homogenization of the Precipitation Series. Daily precipitation data from 1959 to 2015 were collected from 19 national meteorological observation stations in the UHRB (Figure 1; Table 1) and were provided by the National Climate Center (NCC) of the China Meteorological Administration (CMA). The quality of the data was assessed and controlled before its release $[31,32]$. Some values are missing in the daily precipitation datasets. Of the 19 stations, 5 stations have some missing data; in total, the missing data account for less than $0.01 \%$ of the total data. Weather stations with more than 1 year of missing daily precipitation values were excluded from the analysis. The missing values from other stations were processed in the following ways: (1) if precipitation values were missing for only 1 day, the missing value was replaced by the average value of neighbouring days, or (2) 
TABLE 1: Geographical coordinates, annual mean precipitation $(P)$, and mean number of rainy days $(N)$ (daily precipitation $\geq 0.1 \mathrm{~mm})$ for the selected 18 meteorological stations across the UHRB.

\begin{tabular}{|c|c|c|c|c|c|}
\hline Gauge station (abbreviation) & Latitude $\left({ }^{\circ} \mathrm{N}\right)$ & Longitude $\left({ }^{\circ} \mathrm{E}\right)$ & Elevation $(\mathrm{m})$ & $P(\mathrm{~mm})$ & $N$ \\
\hline Wei Ning (WN) & 26.85 & 104.25 & 2316.5 & 900.1 & 191 \\
\hline Shui Cheng (SC) & 26.73 & 104.78 & 1811.7 & 1189.1 & 215 \\
\hline Zhan Yi (ZYI) & 25.58 & 103.83 & 1866.0 & 968.4 & 137 \\
\hline Pan Xian (PX) & 25.78 & 104.65 & 1490.0 & 1362.7 & 191 \\
\hline Yu Xi (YX) & 24.33 & 102.57 & 1671.0 & 892.9 & 139 \\
\hline Lu Xi (LX) & 24.53 & 103.73 & 1704.3 & 910.3 & 141 \\
\hline Meng Zi (MZ) & 23.47 & 103.57 & 1299.0 & 840.2 & 131 \\
\hline Yan Shan (YS) & 23.68 & 104.32 & 1596.4 & 988.6 & 156 \\
\hline An Shun (AS) & 26.23 & 105.92 & 1375.1 & 1312.8 & 188 \\
\hline Du Jun (DJ) & 26.28 & 107.52 & 760.0 & 1427.2 & 186 \\
\hline Xing Ren (XR) & 25.42 & 105.25 & 1400.0 & 1319.2 & 190 \\
\hline Wang Mo (WM) & 25.25 & 105.98 & 500.0 & 1220.4 & 152 \\
\hline Xing Yi (XY) & 25.08 & 105.02 & 1305.0 & 1437.4 & 186 \\
\hline Zi Yun (ZY) & 25.72 & 106.15 & 1489.0 & 1274.2 & 177 \\
\hline Hui Shui (HS) & 26.18 & 106.68 & 949.7 & 1196.7 & 179 \\
\hline Luo Dian (LD) & 25.45 & 106.77 & 405.0 & 1143.7 & 146 \\
\hline Du Shan (DS) & 25.85 & 107.53 & 984.0 & 1312.9 & 187 \\
\hline Feng Shan (FS) & 24.55 & 107.03 & 490.0 & 1524.2 & 162 \\
\hline
\end{tabular}

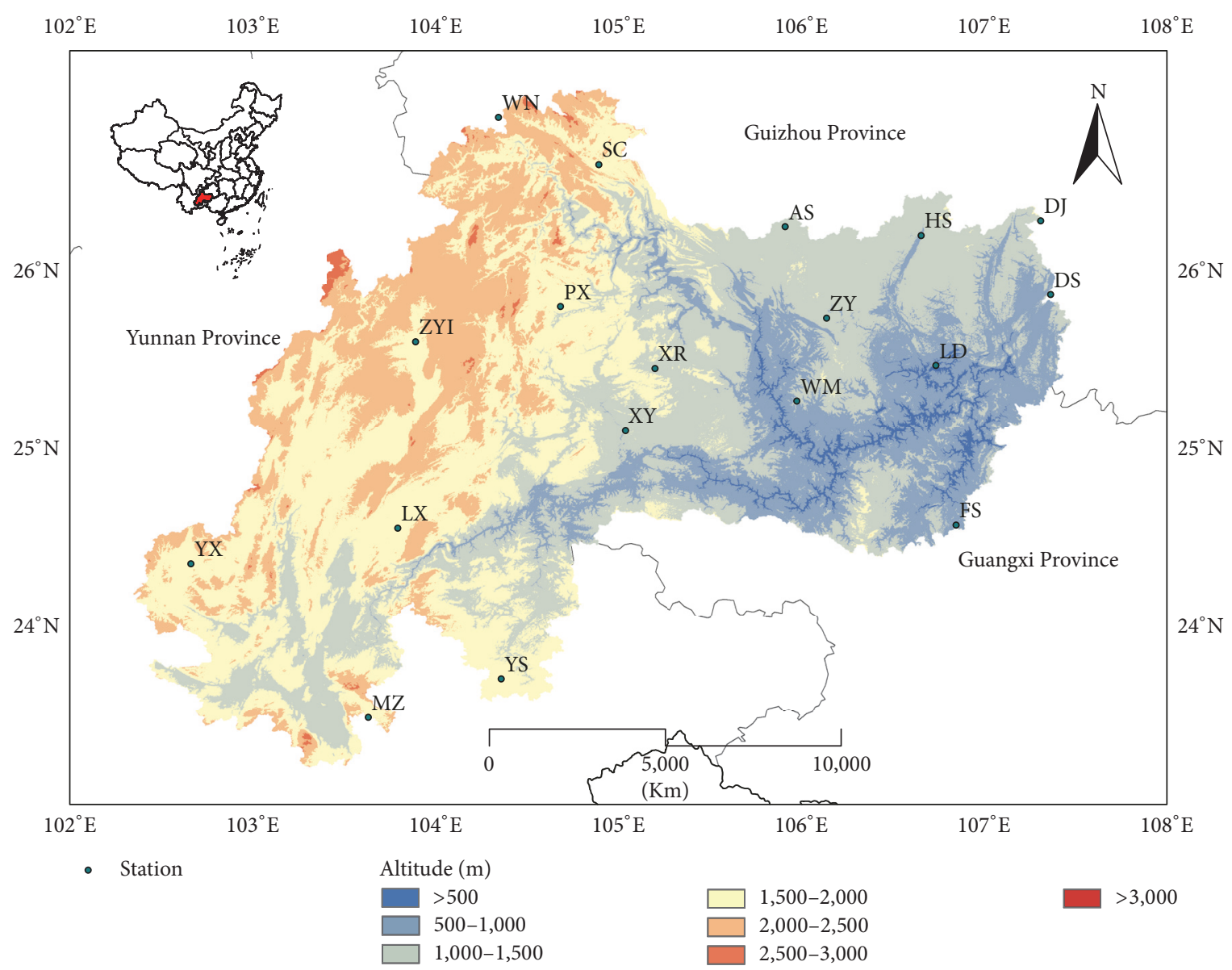

FIGURE 1: Locations of the 18 meteorological stations plotted on a digital elevation model of the upper reaches of the Hongshui River basin, China. 
if consecutive days were missing, values were estimated by simple linear correlation based on data from neighbouring stations $\left(R^{2}>0.95\right)$ [33]. Finally, a quality control evaluation and a homogeneity assessment of daily precipitation data were performed using the software packages RclimDex and RHtests V4 (http://etccdi.pacificclimate.org/software.shtml). These two programs have been widely used in the quality control, homogenization, and extreme index classification of precipitation data $[12,34-38]$. The processes of quality control evaluation and homogeneity assessment include (1) identifying errors in the precipitation data, such as precipitation values below $0 \mathrm{~mm}$; (2) searching for outliers, where we choose 3 standard deviations as the threshold for a fineresolution quality control of the data; (3) using plots of generalized data in RclimDex to visually inspect the data and further identify outliers and a variety of other problems that may cause errors or bias in analysing changes in the seasonal cycles or variance of the data; and (4) using RHtestsV3 to detect artificial shifts that could exist in a time series. Through quality control and homogeneity tests, the integrity of the data used in the analysis can be guaranteed, and the deviations in the analysis caused by changes in observation stations and instruments can be excluded [28, 38, 39]. After rejecting 1 station, 18 weather stations were finally selected for this study.

The large-scale atmospheric circulation indices selected in this paper, such as the Northern Hemisphere Subtropical High (NHSH) $\left(5 \mathrm{E}^{\circ}-360 \mathrm{E}^{\circ}\right)$, Northern Hemisphere Polar Vortex (NHPV) $\left(0-360^{\circ}\right)$, South China Sea Subtropical High $(\mathrm{SCSSH})\left(100^{\circ} \mathrm{E}-120^{\circ} \mathrm{E}\right)$, and Indian Subtropical High (ISH) $\left(65^{\circ} \mathrm{E}-95^{\circ} \mathrm{E}\right)$, were provided by the NCC of the CMA. The East Asian Summer Monsoon index (EASMI) is based on the intensity of the normalized seasonality of the wind field at $850 \mathrm{hPa}\left(10^{\circ}-40^{\circ} \mathrm{N}, 110^{\circ}-40^{\circ} \mathrm{E}\right)$ from June to August [40, 41]. Similarly, the South China Sea summer monsoon index (SCSSMI) is based on the intensity of the normalized seasonality of the wind field at $925 \mathrm{hPa}\left(0^{\circ}-25^{\circ} \mathrm{N}, 100^{\circ}-125^{\circ} \mathrm{E}\right)$ from June to September $[40,41]$. The South Asian summer monsoon index (SASMI) is defined as an area-averaged seasonally (JJAS) dynamical normalized seasonality (DNS) at $850 \mathrm{hPa}$ within the South Asian domain $\left(5^{\circ} \mathrm{N}-22.5^{\circ} \mathrm{N}\right.$, $\left.35^{\circ} \mathrm{E}-97.5^{\circ} \mathrm{E}\right)[40,41]$. The annual EASMI, SCSSMI, and SASMI data were available from the following website: http://ljp.gcess.cn/dct/page/1.

\section{Methodology}

3.1. Method of Calculating the PCI. The PCI evaluates various weights of daily precipitation; specifically, it assesses the contribution of the days with the greatest rainfall to the total amount. The theoretical basis of this approach is that the contribution of the days of a given rainfall level to the total amount is generally adjustable by a negative exponential distribution. Therefore, few large amounts of daily precipitation occur in a given period and place [13]. To assess the effects of different daily precipitation values on total precipitation and the contribution of UHRB precipitation to total precipitation, the cumulative percentage of precipitation $(Y)$ on qualifying days $(X$, a cumulative variable) was analysed $[13,26,29]$.
This paper uses a limit of $0.1 \mathrm{~mm} /$ day to separate wet and dry days and $1 \mathrm{~mm}$ as the precipitation interval to classify the precipitation limits in ascending order. The numbers of days with precipitation totals that fall into each class are counted, and the associated amount of precipitation is computed. Then, the cumulative total precipitation is calculated. Finally, $X$ and $Y$ are obtained in this paper. An exponential curve $X$ versus $Y$ is derived and can be expressed as follows [42, 43]:

$$
Y=a X \exp (b X)
$$

where $a$ and $b$ are constants estimated by the least-squares method. According to Martin-Vide [13], one way of adapting the above curve from (1) is through the following equation:

$$
Y=X \exp \left[-b(100-X)^{c}\right]
$$

where $b$ and $c$ are regression coefficients estimated using the least-squares method with observed precipitation data [44].

Jolliffe and Hope [45] proved that (1) and (2) are probability distributions that are truncated, in the sense that the rainfall values above and below certain thresholds have zero probability of occurrence. Equations (1) and (2) can both generate a polygonal line called the concentration curve or Lorenz curve, which has been widely used in different regions $[26,27,46-49]$. The area $S$ enclosed by the bisector of the quadrant and the polygonal line provides a measure of the concentration. The Gini concentration index, 2S/10000, is used as a concentration measure. The precipitation concentration is based on the Gini coefficient, which is the area bounded by the line of a perfect distribution $\left(45^{\circ}\right)$ and the Lorenz curve. Because the parameters in (1) and (2) have been determined by the least-squares method, the area $S$ in (1) and (2) is the difference between 5000 and the definite integral of the Lorenz curve between 0 and 100. These relationships can be written as follows:

$$
\begin{aligned}
& S=5000-\int_{0}^{100} a x \exp (b x) d x \\
& S=5000-\int_{0}^{100} x \exp \left[-b(100-x)^{c}\right] d x .
\end{aligned}
$$

Then, the PCI, which is similar to the Gini concentration index, can be expressed by

$$
\mathrm{PCI}=\frac{S}{5000} .
$$

Therefore, the PCI value is based on the fraction of $S$ and the surface area of the lower triangle delimited by the equidistribution line [13]. This method will be used to reveal the structure of the cumulative precipitation amounts contributed by the cumulative number of precipitation days. The results of the two exponential models ((1) and (2)) will be compared to determine which is better for estimating the observed cumulative percentage of precipitation in the UHRB. The coefficient of determination $\left(R^{2}\right)$, root mean square error (RMSE), and sum squared residual (SSE) [50] were used to evaluate (1) and (2). The results of the optimal method will be analysed in the following section. 
TABLE 2: Values of RMSE and SSE for (1) and (2), the values of constants $b$ and $c$ in the exponential curves of (2), the PCI, the percentage of precipitation contributed by the top $25 \%$ of rainy days $(P-25 \%)$, and PCD and PCP for each station.

\begin{tabular}{lcccccccccc}
\hline Gauge station (abbreviation) & RMSE $_{1}$ & RMSE $_{2}$ & SSE $_{1}$ & SSE $_{2}$ & $b$ & $c$ & PCI & $P-25 \%$ & PCD PCP $^{\circ}$ ) \\
\hline Wei Ning (WN) & 2.43 & 0.18 & 720 & 3.9 & 0.129 & 0.754 & 0.73 & 82.5 & 0.58 & 202 \\
Shui Cheng (SC) & 2.19 & 0.11 & 830 & 2.0 & 0.132 & 0.738 & 0.72 & 81.8 & 0.55 & 200 \\
Zhan Yi (ZYI) & 2.20 & 0.21 & 854 & 7.9 & 0.110 & 0.731 & 0.67 & 76.5 & 0.55 & 203 \\
Pan Xian (PX) & 2.23 & 0.25 & 740 & 9.1 & 0.105 & 0.807 & 0.72 & 81.7 & 0.58 & 200 \\
Yu Xi (YX) & 1.96 & 0.30 & 375 & 9.0 & 0.095 & 0.788 & 0.67 & 77.3 & 0.55 & 209 \\
Lu Xi (LX) & 2.04 & 0.32 & 534 & 13.1 & 0.099 & 0.755 & 0.65 & 75.5 & 0.55 & 203 \\
Meng Zi (MZ) & 2.12 & 0.22 & 556 & 6.0 & 0.098 & 0.755 & 0.65 & 75.4 & 0.52 & 202 \\
Yan Shan (YS) & 2.00 & 0.26 & 683 & 11.6 & 0.090 & 0.834 & 0.70 & 80.0 & 0.54 & 202 \\
An Shun (AS) & 2.72 & 0.25 & 1371 & 11.4 & 0.144 & 0.735 & 0.74 & 83.9 & 0.53 & 190 \\
Du Jun (DJ) & 2.32 & 0.21 & 1656 & 13.7 & 0.135 & 0.704 & 0.70 & 79.6 & 0.45 & 183 \\
Xing Ren (XR) & 2.31 & 0.10 & 1107 & 2.2 & 0.130 & 0.736 & 0.71 & 81.3 & 0.53 & 196 \\
Wang Mo (WM) & 2.48 & 0.19 & 1260 & 7.2 & 0.133 & 0.752 & 0.73 & 83.2 & 0.54 & 187 \\
Xing Yi (XY) & 2.10 & 0.07 & 1081 & 1.1 & 0.127 & 0.721 & 0.70 & 79.4 & 0.55 & 200 \\
Zi Yun (ZY) & 2.40 & 0.20 & 1057 & 7.2 & 0.126 & 0.770 & 0.73 & 83.4 & 0.53 & 187 \\
Hui Shui (HS) & 2.54 & 0.23 & 1196 & 9.9 & 0.135 & 0.753 & 0.74 & 83.6 & 0.51 & 185 \\
Luo Dian (LD) & 1.95 & 0.20 & 1280 & 14.1 & 0.117 & 0.752 & 0.70 & 79.9 & 0.53 & 183 \\
Du Shan (DS) & 2.29 & 0.10 & 887 & 1.6 & 0.117 & 0.797 & 0.72 & 82.2 & 0.44 & 180 \\
Feng Shan (FS) & 2.27 & 0.16 & 1134 & 5.8 & 0.105 & 0.811 & 0.72 & 81.3 & 0.55 & 189 \\
\hline
\end{tabular}

3.2. Method of Calculating the PCD and PCP. Zhang and Qian [30] proposed the PCP index. The PCP represents the month in which total precipitation in a year is concentrated. The basic concept behind the PCD and PCP indices is that the monthly total precipitation is a vector quantity with both magnitude and direction $[20,28]$. The magnitudes are the total monthly precipitation amounts, and the directions are the angles assigned to each month in $30^{\circ}$ increments, all of which comprise a circle $\left(360^{\circ}\right)$ for a year. The procedure used in this study to calculate the PCP and PCD is as follows $[20,30]$ :

$$
\begin{aligned}
R_{i} & =\sum r_{i j} \\
R_{x i} & =\sum r_{i j} \cdot \sin \theta_{j} \\
R_{y i} & =\sum r_{i j} \cdot \cos \theta_{j} \\
\mathrm{PCP}_{i j} & =\arctan \left(\frac{R_{x i}}{R_{y i}}\right) \\
\mathrm{PCD}_{i j} & =\frac{\sqrt{R_{x i}^{2}+R_{y i}^{2}}}{R_{i}},
\end{aligned}
$$

where $i$ and $j$ are the year $(i=1959,1960, \ldots, 2015)$ and month $(j=1,2, \ldots, 12)$, respectively; $r_{i j}$ represents the monthly total precipitation in the $j$ th month and $i$ th year; and $\theta_{j}$ is the azimuth of the $j$ th month. $\mathrm{PCP}_{i j}$ represents the period (month) in which the total precipitation of the $i$ th year is concentrated, and $\mathrm{PCD}_{i j}$ represents the degree to which total precipitation in the $i$ th year is concentrated over 12 months.

For each station in the study area, annual PCD and PCP values were calculated, and the obtained time series were assessed to determine their temporal changes from 1959 to 2015. Additionally, annual values of PCD and PCP were averaged over the study period to obtain their long-term means.

3.3. Mann-Kendall Trend Test and Autocorrelation Analysis. In this study, the nonparametric Mann-Kendall method [51, 52] was applied to analyse the temporal trends of the three indices discussed. This method is considered appropriate for climate change analysis and has been commonly used for time series analyses of hydrological data, such as water quality, stream flow, and precipitation data [53-56].

Before the Mann-Kendall test was applied, the precipitation indices (PCI, PCD, and PCP) were assessed using a serial correlation analysis. Additionally, a modified prewhitening method proposed by Yue et al. [57] was employed to eliminate the effect of serial correlation in series with significant autocorrelation. The detailed procedures of the serial correlation analysis and the modified prewhitening method can be found in the work of Yue et al. [57].

\section{Results}

4.1. Spatial Patterns of the PCI, PCP, and PCD. PCI values were estimated for all stations throughout the Hongshui River basin from 1959 to 2015. After comparing the performance of (1) with that of (2), it was found that (2) better estimated the cumulative percentage of the precipitation variation, and the Lorenz curve was applied to determine the extent of precipitation differences in the UHRB. The following discussion is based on the results of (2). Table 2 shows the values of regression coefficients $b$ and $c$ used in (2). These coefficients were estimated via the least-squares method. 
For illustrative purposes, Figure 2 compares the observed and estimated cumulative precipitation percentages of six representative stations: WN station, representing the northern UHRB; YX station, representing the western UHRB; YS station, representing the southern UHRB; DS station, representing the eastern UHRB; and XY and XR stations, representing the central UHRB. The RMSE and SSE results of (1) and (2) are also shown in Table 2. Since the $R^{2}$ of values of (1) and (2) are both above 0.99 , the difference between them is not obvious, so the result is not listed in Table 2. By comparing the RMSE and SSE results, we can observe that the results of (2) are obviously superior to those of (1) for all stations. The results show that (2) fits the observed data better than (1) and can be effectively used to estimate precipitation changes in the UHRB. Similar results were obtained for all stations in the study region. The spatial distribution of the average PCI is shown on the map in Figure 3. These values can be used to determine the spatial patterns of daily precipitation concentrations in the UHRB.

The annual PCI ranges between 0.65 and 0.74 and varies across the UHRB in a broad northeast to southwest gradient (Figure 3(a)). The concentration degree of regional precipitation is generally high, and the spatial distribution of the PCI obviously differs from east to west. The northeast portion of the UHRB includes stations with high PCIs. The PCI values in the northeastern region of the UHRB are generally greater than 0.7 , such as those at the AS and HS stations, with a maximum value of 0.74 . However, other regions exhibit low precipitation concentrations. The low PCI values are centered in the southwestern portion of the basin, and the lowest value is 0.65 at the MZ and LX stations. Figure 3 (b) shows the percentage of precipitation contributed by the top $25 \%$ of rainy days. In Figure 3(b), the spatial and temporal distributions of precipitation are highly variable throughout the basin. The annual precipitation contribution of the top $25 \%$ of rainy days at all stations in the UHRB reached $80.5 \%$. Among these values, the maximum value is $83.9 \%$ at $\mathrm{WN}$ station in the northern portion of the basin, and the minimum value is $75.4 \%$ at $\mathrm{MZ}$ station in the southern portion of the basin. With PCI values greater than 0.70 , the cumulative fraction of precipitation in the highest quartile is $80 \%$ or more.

Figure 3(c) shows the spatial distribution of the average PCD in the river basin. The average annual PCD at each site is between 0.44 and 0.58 , and the annual average for the entire basin is 0.53 , which indicates that the total precipitation in the area is relatively concentrated in a certain period. From the geographical distribution, the PCD values in the northwestern portion of the basin are generally larger than those in the southeast. The DS station, which is located in the eastern part of the basin, has a minimum PCD value of 0.44 . The maximum value of PCD is 0.58 at $\mathrm{WN}$ station, which is located in the northernmost part of the basin, and a large value of approximately 0.54 can be observed in the central portion of the basin.

The PCP variations in the UHRB range from $180^{\circ}$ to $209^{\circ}$ (Figure $3(\mathrm{~d})$ ). The annual precipitation is mainly concentrated from the end of June to the beginning of August each year, and the middle of July is the most concentrated period of precipitation throughout the year. The basin is roughly bounded by the $195^{\circ}$ PCP contour (i.e., July 15), which exhibits distinct characteristics from east to west, indicating that the eastern rainy season is earlier than that in the west. The minimum and maximum PCPs were observed at DS station $\left(180^{\circ}\right)$ in the eastern UHRB and YX station $\left(209^{\circ}\right)$ in the western UHRB. The interval between the maximum precipitation values at DS and YX is approximately 30 days.

\subsection{Spatial Distributions of the PCI, PCP, and PCD Trends.} Figure 4 shows the PCI, PCD, and PCP trends at 18 stations across the study area during the study period from 1959 to 2015. The results of trend analyses are shown in Table 3. Figure 4(a) is the spatial distribution of PCI variations at 18 meteorological stations in the UHRB. The PCI values of most stations (except for WN and YX) in the basin exhibit positive trends, but only 3 stations passed the significance test. The DS $(p<0.05)$ and LD $(p<0.05)$ stations in the eastern part of the UHRB, as well as MZ $(p<0.05)$ station in the southwest, exhibited significant increasing trends, with linear rates of change between $0.005 /$ decade and $0.011 /$ decade. However, YX $(p<0.05)$ station located in the western part of the basin exhibited a significant decreasing trend of $-0.015 /$ decade.

Figure 4(b) shows the spatial distribution of the PCD trend. An increasing trend can be observed in the eastern portion of the basin, and a decreasing trend occurs in the western region. Although the eastern and western regions of the basin exhibit opposing PCD trends, the associated rates of change are small. Only ZYI station exhibited a significant increasing trend, and the rate of change passed the significance test at the 0.05 level.

Figure 4(c) shows the spatial distribution of the PCP variation trend. The overall PCP trend in the basin is decreasing, and most sites (except for LD and PX) do not pass the significance test at the 0.05 level. Among them, the trends at LD and PX decreased significantly by $-0.033^{\circ} /$ decade and $-0.034^{\circ} /$ decade, respectively. The decrease in PCP in the basin suggests that the time of concentrated precipitation has become earlier over time.

4.3. Influence of Geographical Features on Precipitation and the Concentration Indices. Figure 5 provides scatter plots of annual precipitation and the three precipitation concentration indices (PCI, PCD, and PCP) versus latitude, longitude, and elevation. Longitude is the most important of the three variables governing the geographical distribution of mean annual precipitation and the three precipitation concentration indices, followed by elevation (except for the PCI).

To further understand the spatial variations in precipitation and the precipitation concentration indices, the Pearson correlation coefficient was used to analyse the relationship between each precipitation concentration index and geographical factors. The correlations between the annual trends in precipitation and concentration indices and geographical features are shown in Table 4.

The annual mean precipitation is negatively correlated with elevation $(p<0.05)$ and positively correlated with longitude. However, the PCI is negatively correlated with elevation and is positively related to the average annual precipitation 


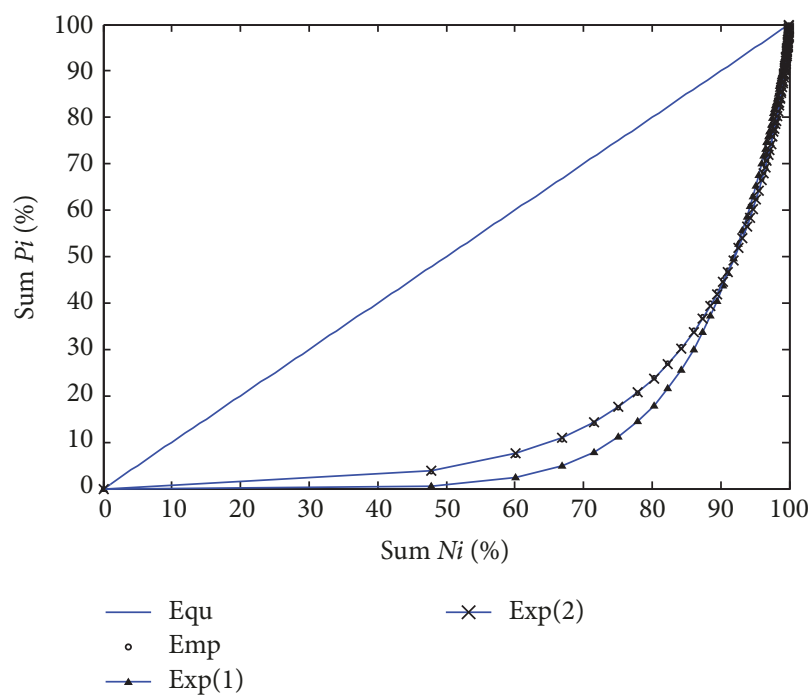

(a)

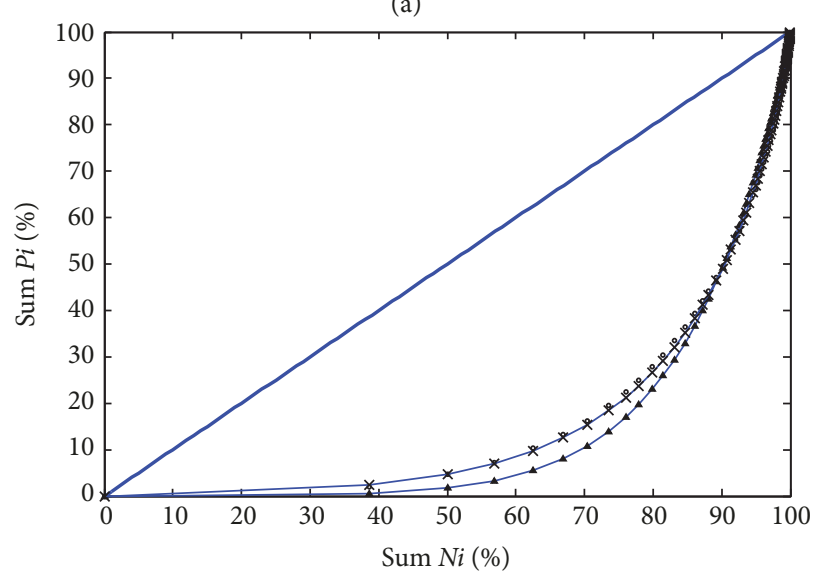

- Equ

$\times \quad \operatorname{Exp}(2)$

- Emp

$\rightarrow \operatorname{Exp}(1)$

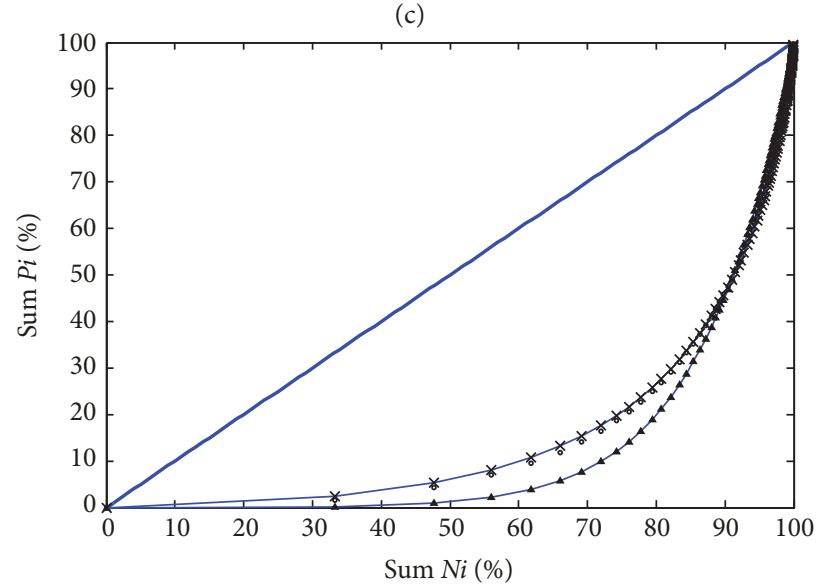

$\begin{array}{ll}- & \text { Equ } \\ \circ & \text { Emp } \\ \ldots & \text { Exp }(1)\end{array}$

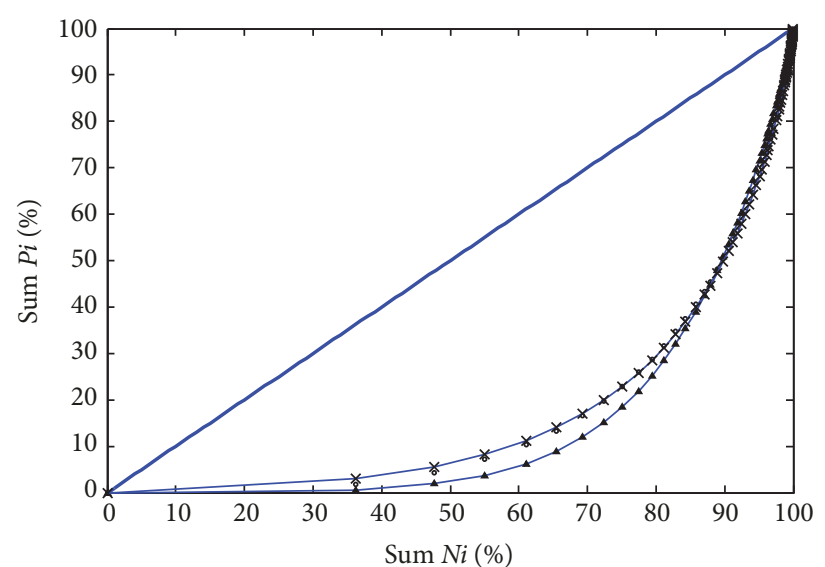

- Equ

$-\operatorname{Exp}(2)$

$\simeq \operatorname{Exp}(1)$

(b)

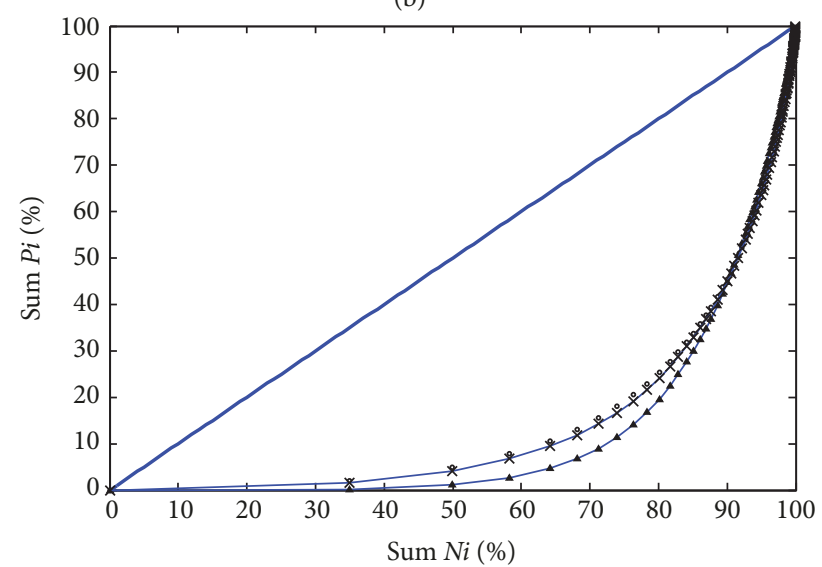

_ Equ

$\times \quad \operatorname{Exp}(2)$

- Emp

$\rightarrow \operatorname{Exp}(1)$

(d)

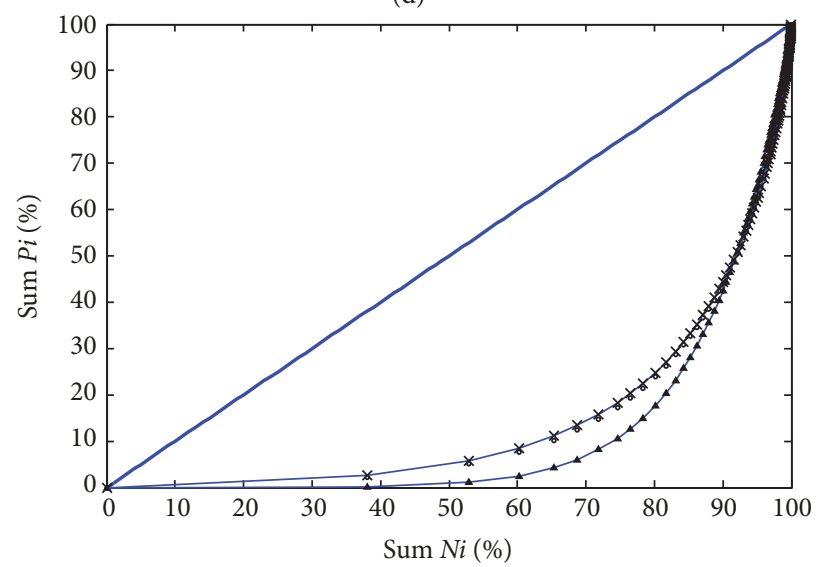

$$
\begin{array}{ll}
- & \text { Equ } \\
\therefore & \text { Emp } \\
\rightarrow & \operatorname{Exp}(1)
\end{array}
$$

(f)

FIGURE 2: Lorenz curves for precipitation observations. (a) WN station, (b) YX station, (c) YS station, (d) DS station, (e) XY station, and (f) XR station. The straight line denotes the equidistribution line, circles denote empirical values (observed precipitation), the line with triangles denotes the exponential values calculated by (1), and the line with crosses denotes the exponential values calculated by (2). $P i$ is the precipitation on day $i=1, \ldots, n$. Ni is the day (period from 1959 to 2015). 


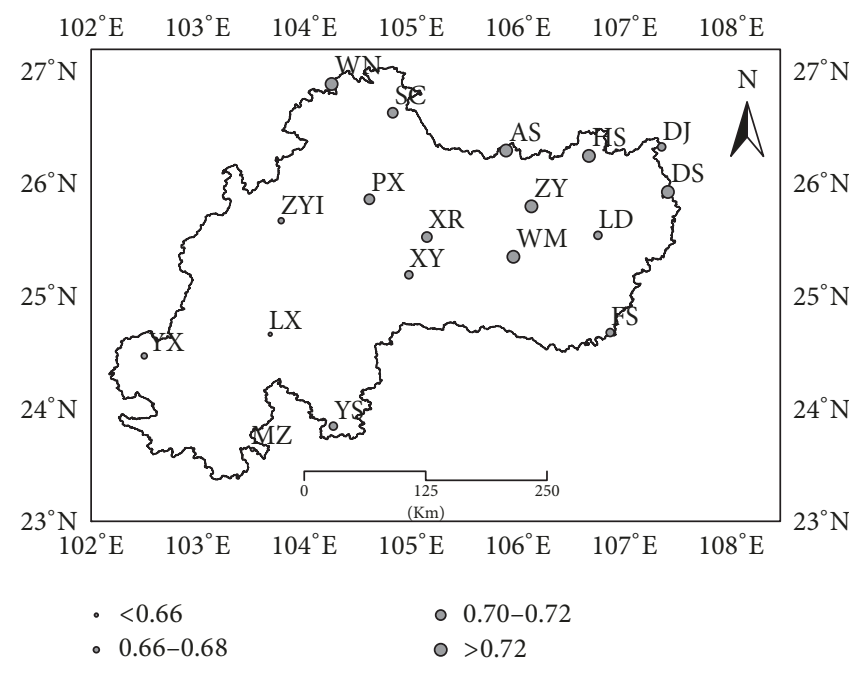

(a) Mean PCI

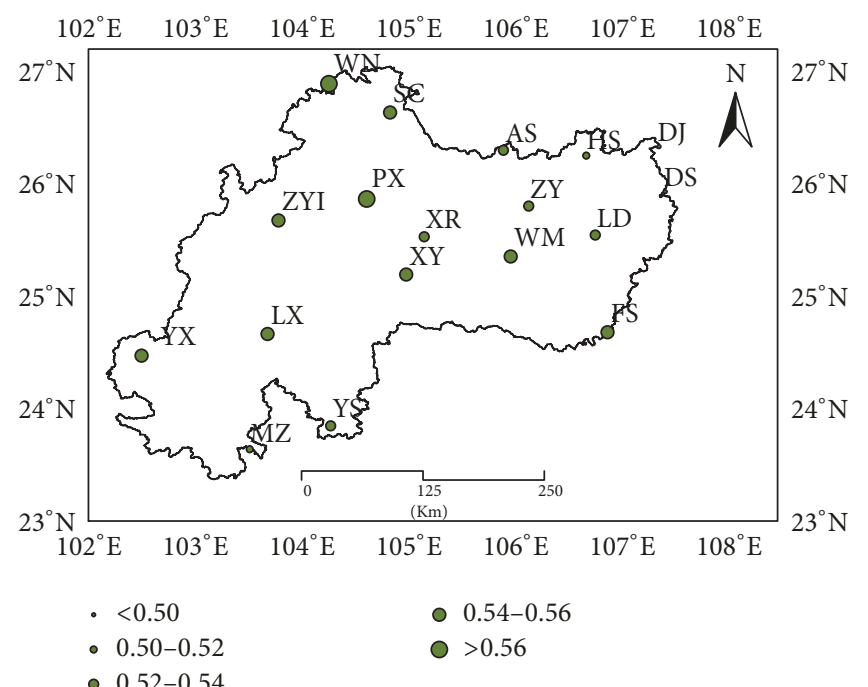

(c) Mean PCD

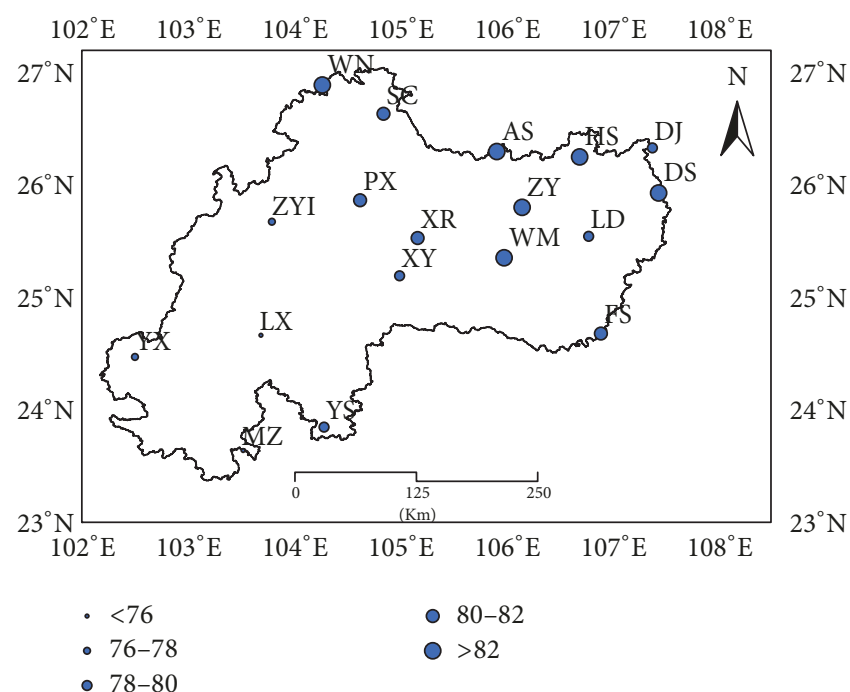

(b) Mean $P-25 \%$

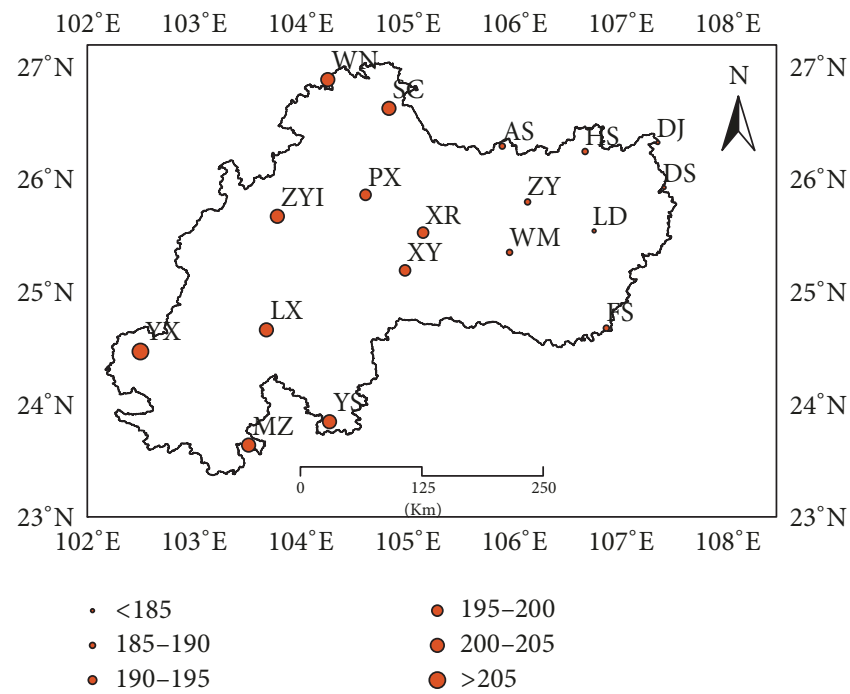

(d) Mean PCP

FIGURE 3: Spatial distribution of the mean annual precipitation concentration index (PCI) (a); mean annual percentage of precipitation contributed by the top $25 \%$ of rainy days $(P-25 \%)(b)$; mean annual precipitation concentration degree (PCD) (c); and mean annual precipitation concentration period (PCP) (d) in the UHRB from 1959 to 2015.

$(p<0.01)$, longitude $(p<0.01)$, and latitude $(p<0.01)$. A significant negative correlation exists between the PCD and longitude $(p<0.01)$, but no significant relationship exists with other factors. This result suggests that precipitation in the western part of the basin is more concentrated in a certain period of time and that the concentration in the east is lower than that in the west. The PCP is significantly negatively correlated with longitude $(p<0.01)$ and precipitation and positively correlated with elevation $(p<0.01)$. Additionally, the PCP value in the eastern plain region is small; therefore, the rainy season will be much earlier than in the west.

4.4. Correlations between Precipitation-Related Indices, LargeScale Atmospheric Circulation Indices, and Summer Monsoon Indices. The relationships between precipitation-related indices and large-scale atmospheric circulation indices and summer monsoon indices are shown in Tables 5, 6, 7, and 8. Annual precipitation (Table 5) exhibits a significant positive relationship with ISH but nonsignificant relationships with NHSH, NHPV, and summer monsoon indices (except EASMI). This result indicates that when the NHSH is strong, annual precipitation may increase, and vice versa. For the PCI (Table 6), most sites display significant negative correlations with NHSH, SCSSH, and the Western Pacific Subtropical High (WPSH) and nonsignificant negative correlations with ISH and NHPV. Moreover, the PCI does not exhibit a significant relationship with the summer monsoon indices, and only YX station in the western part of the basin displays significant positive correlations with SASMI and SCSSMI. Table 7 shows that the ISH has a significant 


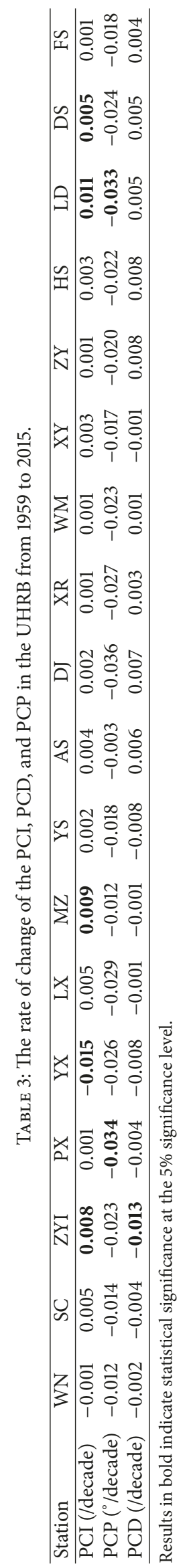




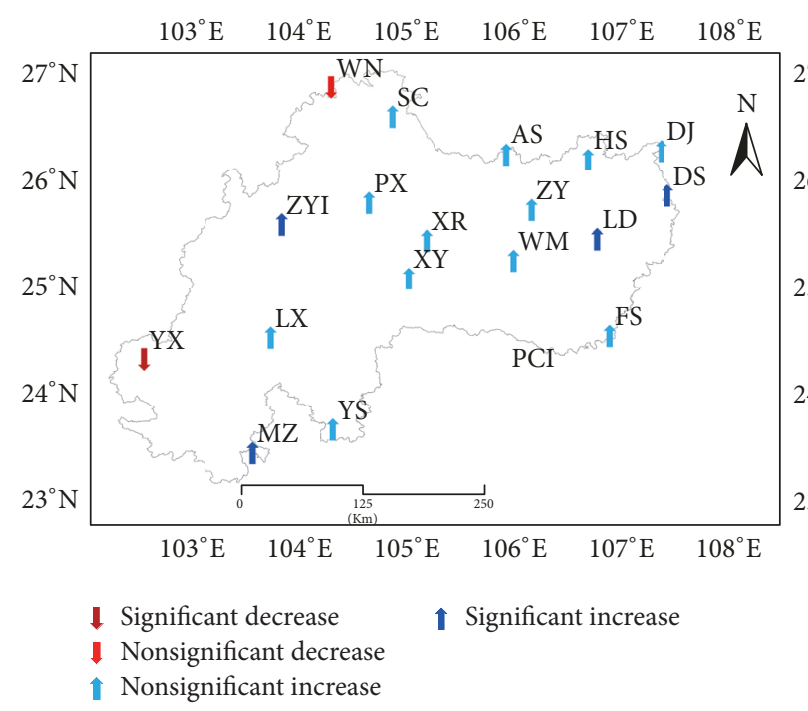

(a)

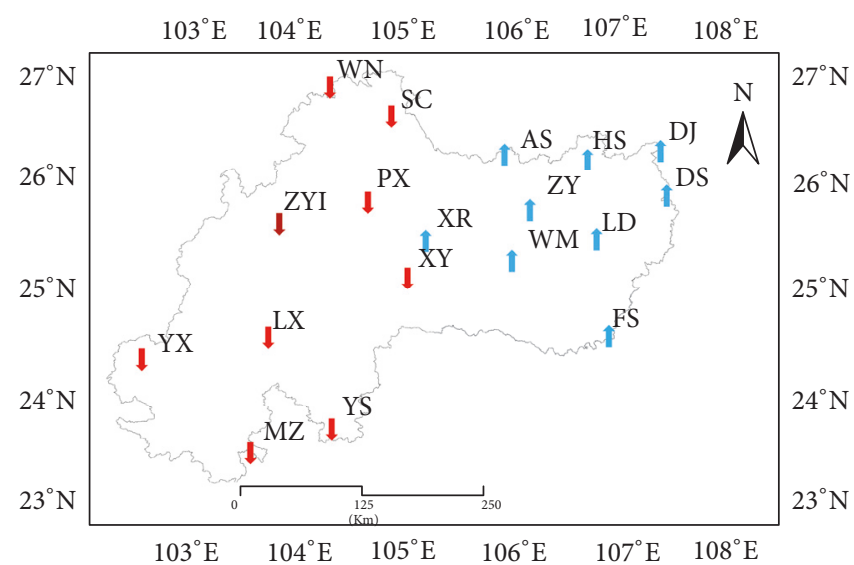

Significant decrease
Nonsignificant decrease
1 Nonsignificant increase

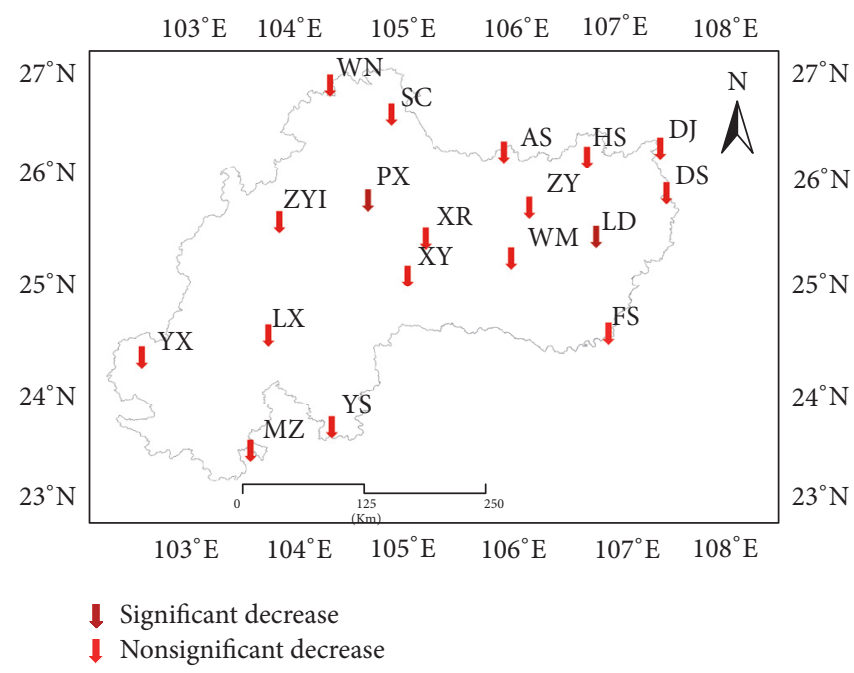

(c)

FIGURE 4: Spatial distributions of the observed PCI (a), PCD (b), and PCP (c) trends in the UHRB from 1959 to 2015.

TABLE 4: Pearson's correlation coefficients between the geographical features of the UHRB, precipitation indices (PCI, PCD, and PCP) and annual precipitation.

\begin{tabular}{lcccc}
\hline Geographical features & PCI & PCD & PCP & Annual precipitation \\
\hline Latitude & $0.66^{* *}$ & -0.08 & -0.39 & 0.35 \\
Longitude & $0.64^{* *}$ & $-0.60^{* *}$ & $-0.97^{* *}$ & $0.74^{* *}$ \\
Elevation & -0.23 & 0.47 & $0.76^{* *}$ & $-0.56^{*}$ \\
\hline
\end{tabular}

${ }^{* *}$ Significant at the 0.01 level; ${ }^{*}$ significant at the 0.05 level.

positive correlation with the PCD at most sites and the correlation is stronger than that of annual precipitation. In addition, the summer monsoon indices, NHSH, WPSH, and NHPV, exhibit significant relationships with PCD values, but it is difficult to determine whether the main relationship between the PCD and atmospheric circulation indices is positive or negative because it is affected by spatial properties. In addition, some of the PCP values exhibit significant negative correlations with NHPV, SCSSH, and WPSH, and the correlation coefficient of SCSSH is higher than those of NHPV and WPSH (Table 8). This finding suggests that $\mathrm{SCSSH}$ is one of the main factors that affects PCP variations. 


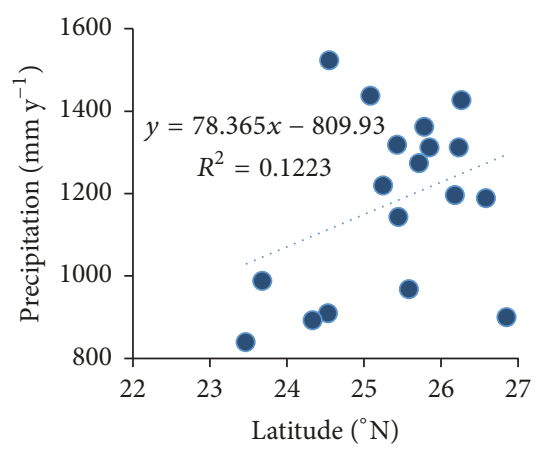

(a) Precipitation: latitude

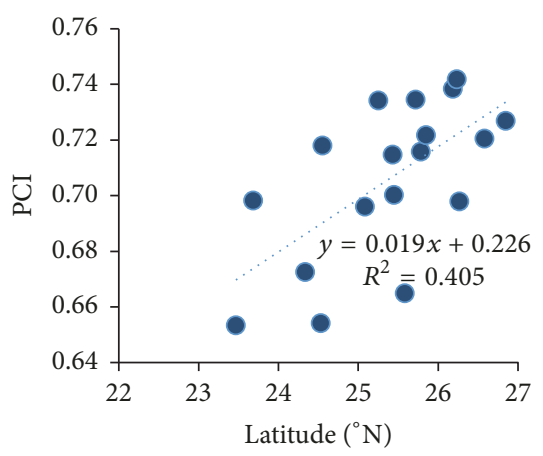

(d) PCI: latitude

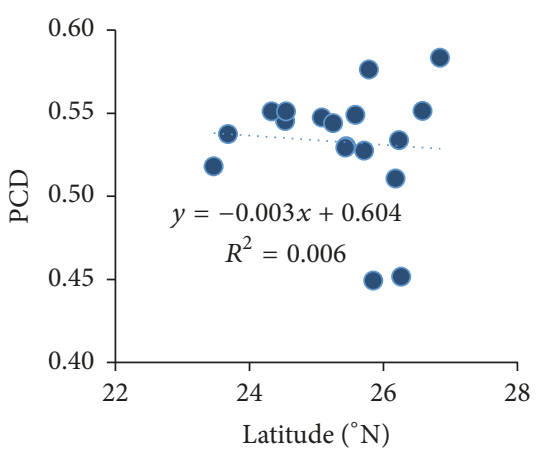

(g) PCD: latitude

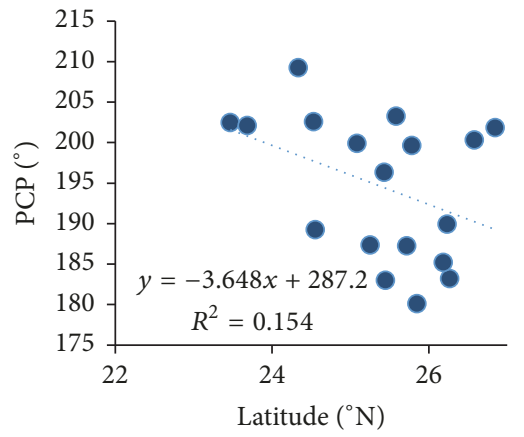

(j) PCP: latitude

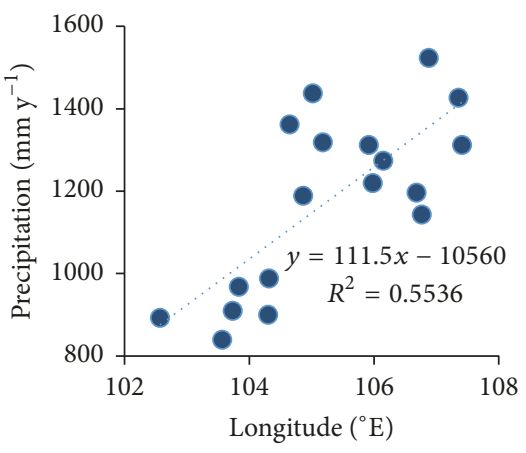

(b) Precipitation: longitude

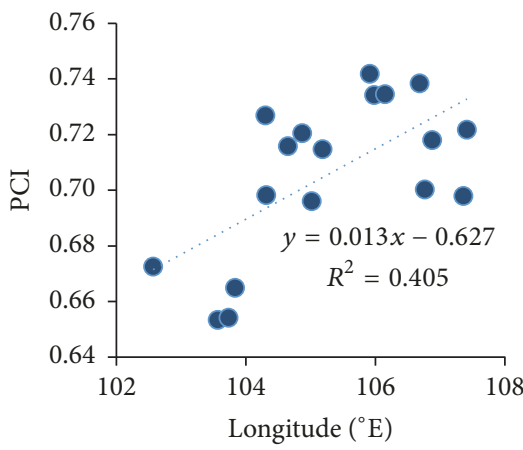

(e) PCI: longitude

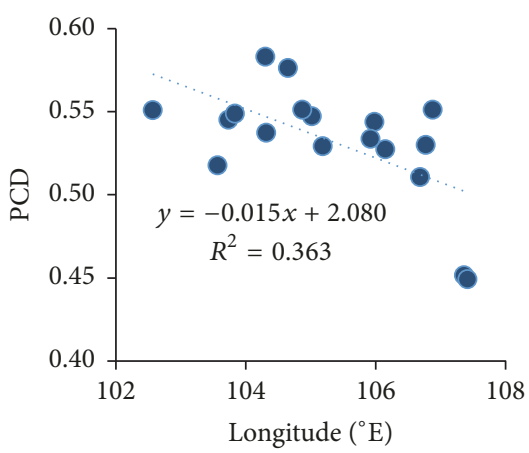

(h) PCD: longitude

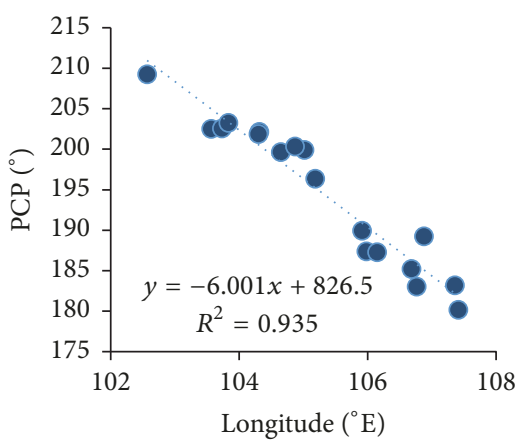

(k) PCP: longitude

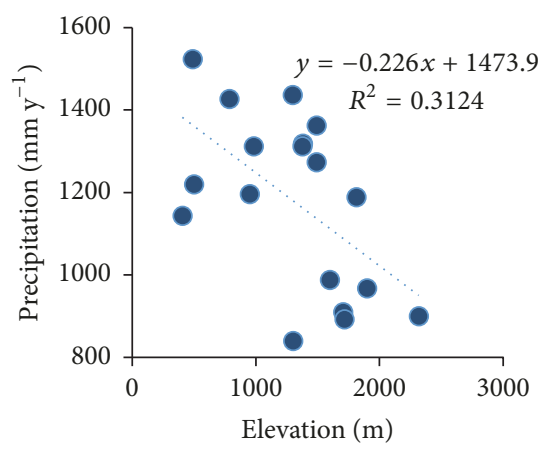

(c) Precipitation: elevation

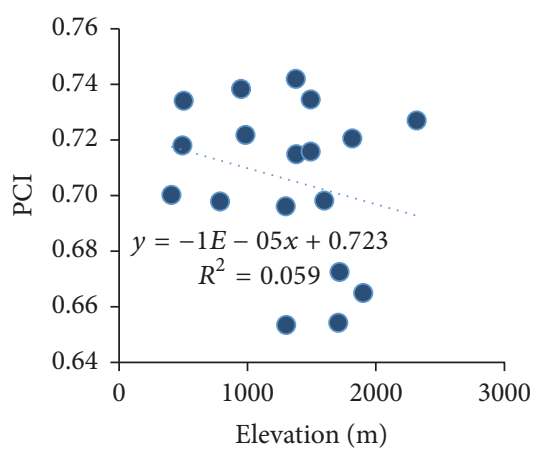

(f) PCI: elevation

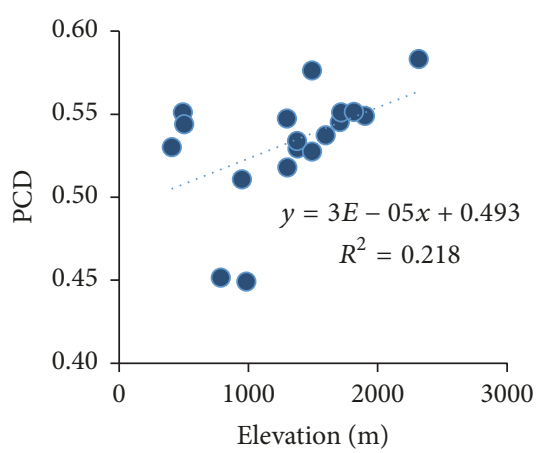

(i) PCD: elevation

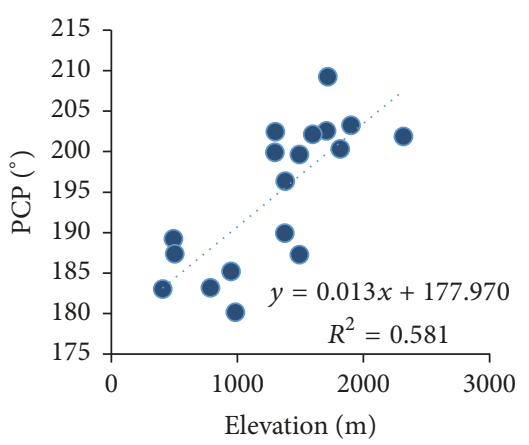

(l) PCP: elevation

FIGURE 5: Correlations between geographical features (from left to right: latitude, longitude, and elevation) and (a-c) mean annual precipitation, (d-f, g-i, and j-l) PCI, PCD, and PCP, respectively. 


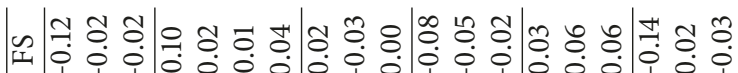
מ

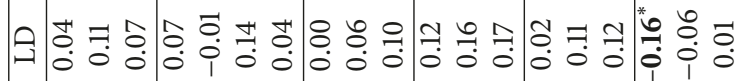

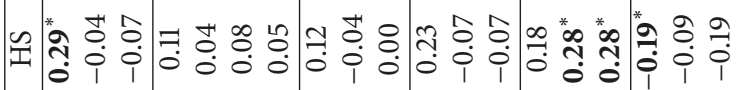

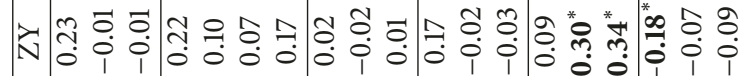

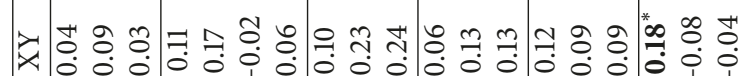

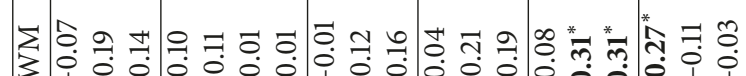

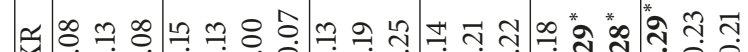
$\overline{\mathrm{A}}$

万人

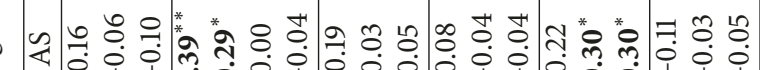

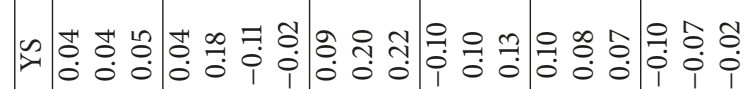

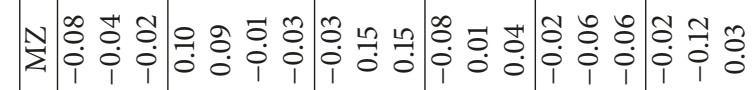

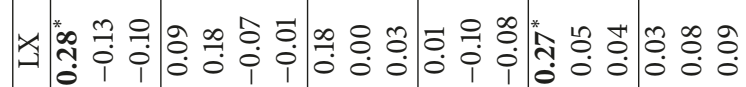
ঝ ঝ

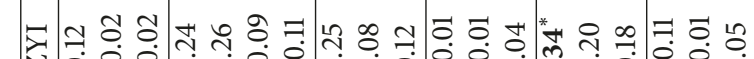

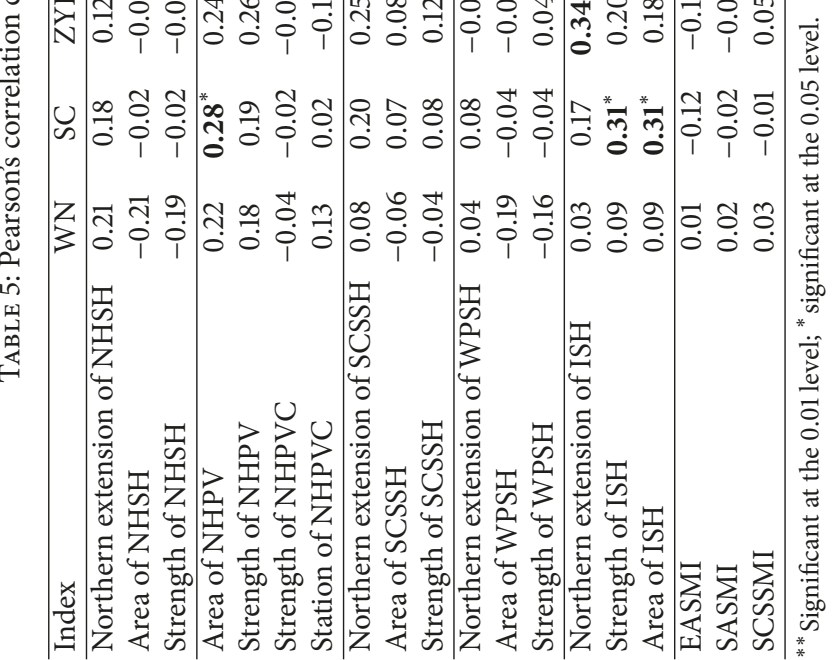




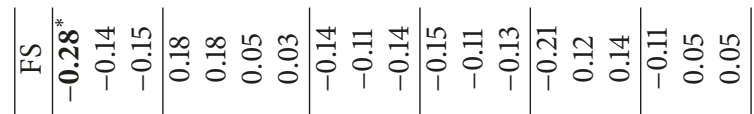

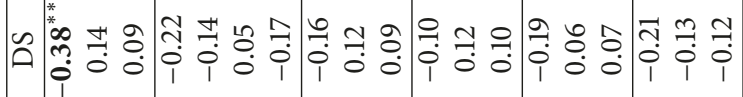

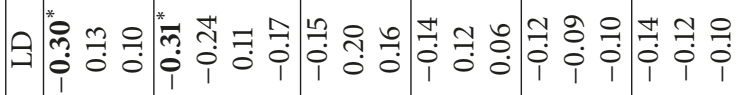

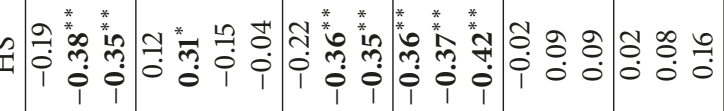

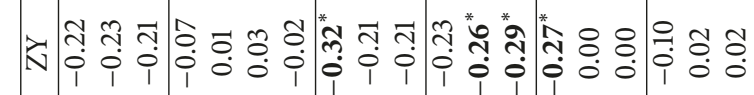

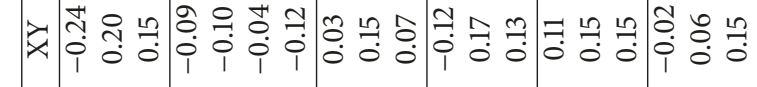

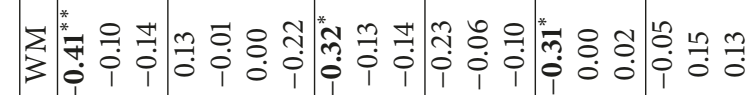

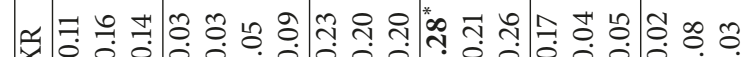

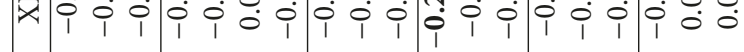

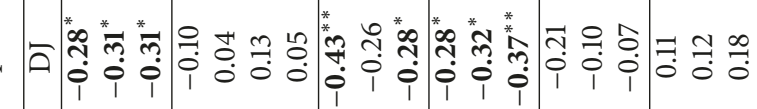

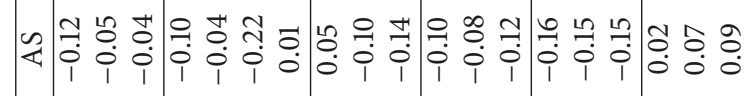

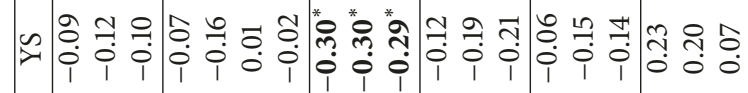

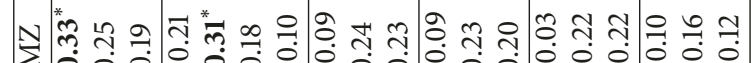
I . ×

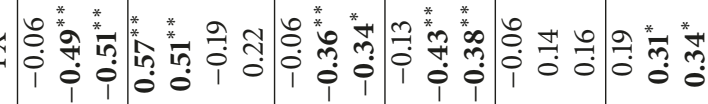
×

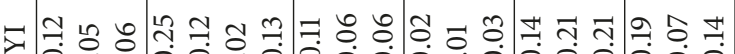

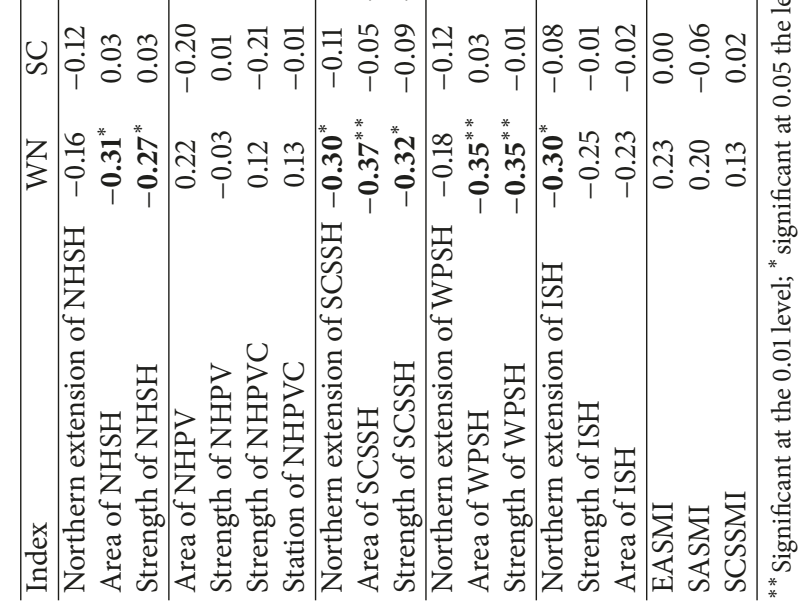




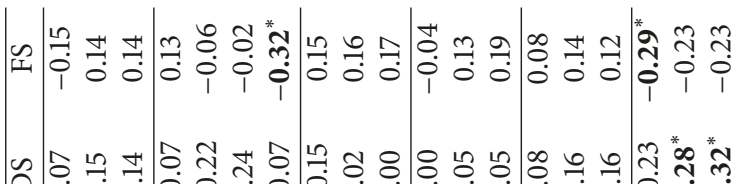

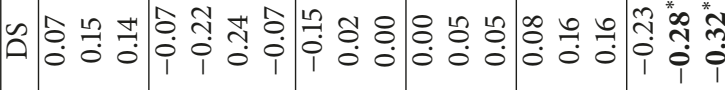

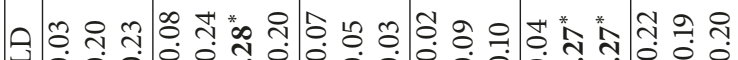
幽 .

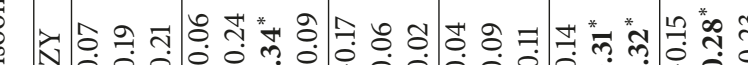

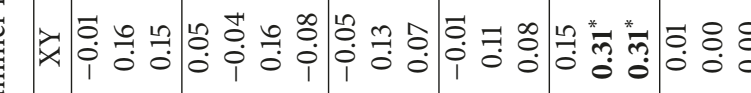

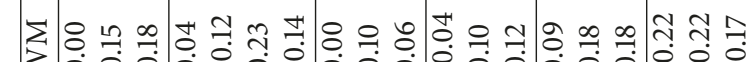

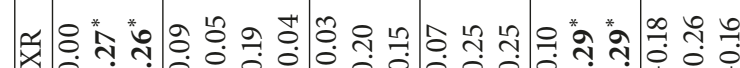

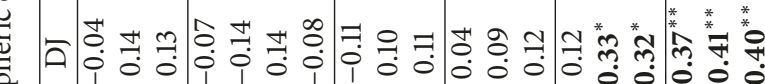

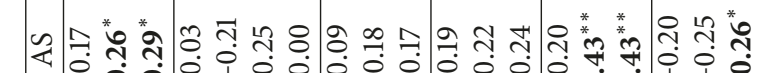

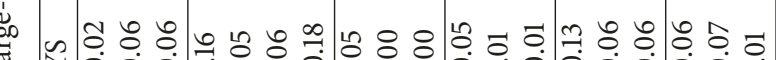
?

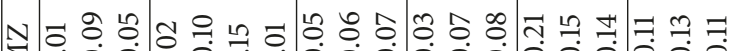

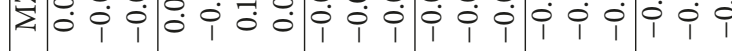

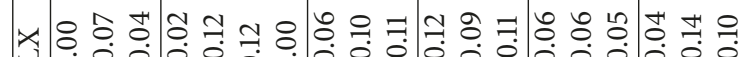

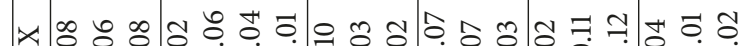

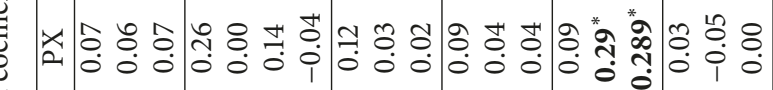

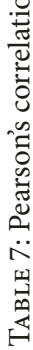

在

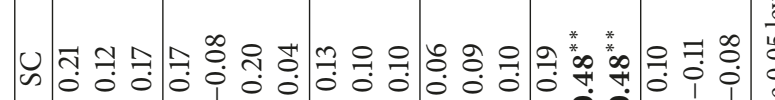

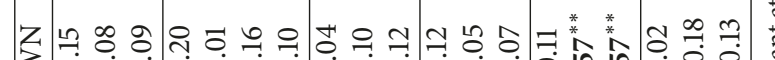

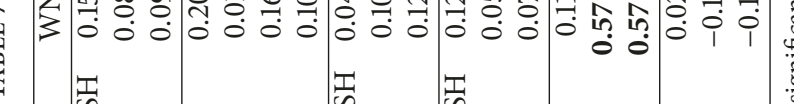

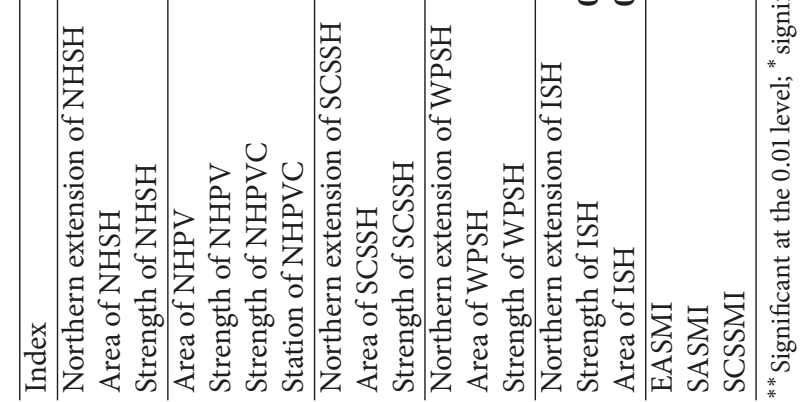




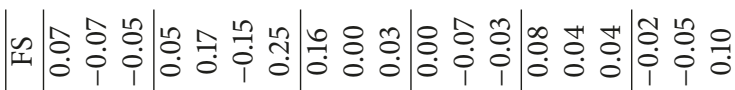

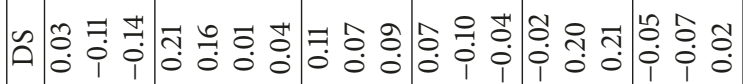

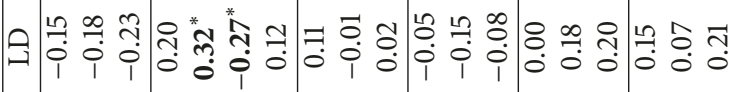




\section{Discussion}

Annual precipitation in the UHRB displays both spatial and temporal variations. During the period analysed (1959-2015), a general decreasing pattern of annual precipitation was observed in the UHRB by Huang et al. [58]. Generally, it has been suggested that the precipitation trends observed in most parts of the world have the same trend sign as annual maximum daily events, but with the trend of heavy precipitation being disproportionately larger than the overall trend [59]. Furthermore, Karl and Trenberth [60] suggested that, even without any change in total precipitation, the frequency of intense daily precipitation can increase in areas with warm climates, which can lead to an increase in the precipitation concentration. Based on the above results, we can speculate that precipitation in the UHRB should have been less concentrated during past decades, but we found no clear signal of changes in the daily concentration in the UHRB during the 1959-2015 period.

A decrease in precipitation during the wet period can have severe effects on the hydrological cycle and water supply for ecosystems and society. In fact, a change in the precipitation quantity results in changes in runoff and affects groundwater recharge rates, which, in turn, affect the water supply. In terms of the agricultural demand, both rainfed and irrigated crops may face soil moisture deficits associated with low precipitation. Changes in runoff also have a significant effect on the output of hydropower generation. As a result, the temporal distribution of precipitation can produce noticeably different effects on natural and social processes across the UHRB, and such variations are of particular interest for water management, flood planning, soil erosion prevention, water availability assessment in natural ecosystems, and so on.

Among the geographical features of the UHRB, longitude is the most important variable that affects the spatial distribution of precipitation. Due to terrain factors and the influence of water vapour transport channels, the spatial distribution of precipitation in the basin significantly differs. Generally, the UHRB terrain is tilted from northwest to southeast. The northwestern portion of the basin is the Yunnan-Guizhou Plateau, the central basin is hilly, and the southeastern region is plains. This terrain is conducive to the flow of water vapour to the mainland, but water vapour transport is hindered by the northwest plateau, making the PCD and PCP values in the northwest significantly higher than those in the southeastern region. In fact, due to different water vapour transmission channels, the geographical factors that affect the temporal and spatial distributions of precipitation will differ. For example, latitude is the main geographical factor that influences annual precipitation changes in Portugal, which is located in the Mediterranean basin [61]. Additionally, the Bay of Bengal is located to the southwest of the UHRB, and the South China Sea is located to the southeast; therefore, the UHRB is jointly influenced by the South Asian monsoon and the East Asian monsoon. The steady stream of water vapour transport from the South China Sea and the Bay of Bengal from April to October each year results in abundant precipitation, which makes the concentration of precipitation significantly different in the southeast and northwest.
The changes in large-scale atmospheric circulations and monsoon activities play important roles in regional precipitation. In recent years, there have been frequent droughts in southwest China that have caused extensive economic losses [62]. Meteorologists [63-65] suggested that droughts during rainy seasons were caused by the westward shift of the enhanced WPSH, which blocked the transfer of warm and humid moisture from the Bay of Bengal to southwest China. Meanwhile, the meridional water vapour flux from the Bay of Bengal was weak. Our results show that the PCD and ISH exhibit a significant positive relation and are negatively correlated with the intensity of monsoons. As the monsoons weaken, future PCD values will gradually increase, and the precipitation will become more concentrated in one period. Currently, all the sites with significant relationships are located in the eastern part of the basin, and the historical analysis shows that the PCD in the eastern region is currently in a weak upward trend. The risk of drought in the future is likely to increase, especially in the east.

Fischer et al. [66] indicated that East Asian summer monsoon was one of the key elements of the climate system and strongly affected precipitation changes in most regions of China. According to the analysis of precipitation and summer monsoon indices, we found that only some eastern sites exhibited significant positive correlations with this monsoon system. Additionally, we found that the PCI had a significant relationship with multiple circulation factors, but the difference in significance was obvious in different regions. These results reflect the complexity of regional precipitation change, but the detailed mechanisms require future study.

\section{Conclusions}

The UHRB is characterized by an area vulnerable to climate change and exhibits obvious differences in the spatial distribution of precipitation. The heterogeneous distribution of precipitation is likely to be further driven by climate warming, which affects the water cycle. Thus, precipitation patterns, including intensity and probability trends, are expected to change, and extreme weather events will likely become more frequent. Therefore, detailed investigations of the characteristics of the precipitation concentration in the UHRB are important for reducing climate-induced flood and drought risks and coping with the associated effects. Based on daily precipitation time series from 18 stations, changes in the PCI, PCD, and PCP across the UHRB and the associated spatial patterns from 1959 to 2015 were analysed in this study. Moreover, the correlations among annual precipitation, the precipitation concentration indices, and geographical features were analysed. The major findings of the article can be summarized as follows:

(1) The model $Y=X \exp \left[-b(100-X)^{c}\right]$ can adequately represent the statistical structure of precipitation rates better than the model $Y=a X \exp (b X)$ in the UHRB. The basin PCI exhibits a gradient from west to east, with higher values in the west and smaller values in the east. The study results also indicate that a large percentage of precipitation is provided by the highest quartile of rainy days. The distribution of precipitation in the UHRB is extremely heterogeneous, and 
the top $25 \%$ of precipitation days at 18 stations in the basin contributed to more than $75 \%$ of the annual precipitation.

(2) In the trend analysis, the PCI and PCD in the basin displayed nonsignificant increasing trends, and the annual distribution of precipitation gradually increased at a slow rate. By contrast, the PCP exhibited a weak decreasing trend at a rate of $0.002^{\circ} /$ decade, indicating that the rainy season occurred earlier over time. The results suggest that the daily precipitation distribution did not significantly change in the UHRB during the 1959-2015 period. However, the decrease in annual precipitation does not mean that the risk of flood disasters also decreased. In fact, the increases in the PCD and PCI indicate that the flood disaster potential increased in the basin.

(3) The PCI, PCD, and PCP are significantly correlated with longitude, and the spatial differences in the indices in the eastern and western regions are large. Among them, the PCI and annual precipitation exhibit significant positive correlations with longitude $(p<0.01)$, and the PCD and PCP display significant negative correlations with longitude $(p<0.01)$. These results indicate that precipitation gradually increases from west to east, and the contribution of heavy precipitation to precipitation has gradually increased over time. Moreover, the rainy season occurs earliest in the east, but the temporal uncertainty of concentrated precipitation is relatively high.

Overall, the investigation of the PCI, PCD, and PCP reveals the characteristics of daily precipitation in the UHRB. These research findings are of considerable importance for local water resources management, and they provide a scientific basis for the development of policy for the mitigation of natural disasters such as floods and droughts. This study uses a statistical analysis of indices of precipitation concentrations to analyse the characteristics of precipitation. However, these results reflect the complexity of regional precipitation change. For example, the physical mechanisms associated with changes in precipitation concentrations are complex and the result of the influence of multiple factors, including a combination of UHRB geographical features, changes in largescale atmospheric circulation and summer monsoon indices and perturbations linked to human activities. The detailed mechanisms that affect the change of precipitation characteristics need further research. Future research will focus on the physical mechanisms that underlie the spatiotemporal distributions of precipitation concentration indices, quantitative analyses of the contributions of atmospheric circulation factors to precipitation change, and simulations of future variations in precipitation concentrations based on regional climate models. Further studies must be conducted to fully understand the responses of water systems to climate change and assess the relationships between precipitation anomalies and precipitation variations in the UHRB.

\section{Conflicts of Interest}

The authors declare that there are no conflicts of interest regarding the publication of this paper.

\section{Authors' Contributions}

Ya Huang conducted the study, analysed the data, and wrote the first draft of the manuscript. Hao Wang, Weihua Xiao, and Li-hua Chen developed the study concept, provided oversight throughout the study, and revised the manuscript. Deng-hua Yan provided valuable comments in revising the manuscript. Yu-yan Zhou, Da-chuan Jiang, and Ming-zhi Yang assisted in the data analysis.

\section{Acknowledgments}

The research was jointly funded by the National Key Research and Development Program (during the 13th Five-Year Plan) (no. 2016YFA0601500) and the National Natural Science Foundation of China (no. 51669003).

\section{References}

[1] I. P. O. C. Change, "Climate change 2007: synthesis report," Environmental Policy Collection, vol. 27, no. 2, article 408, 2008.

[2] C. Chou and C. W. Lan, "Changes in the annual range of precipitation under global warming," Journal of Climate, vol. 25, no. 1, article 1230, 2011.

[3] Y. Gao, L. Cuo, and Y. Zhang, "Changes in moisture flux over the tibetan plateau during 1979-2011 and possible mechanisms," Journal of Climate, vol. 27, no. 5, pp. 1876-1893, 2014.

[4] A. M. Fowler and K. J. Hennessy, "Potential impacts of global warming on the frequency and magnitude of heavy precipitation," Natural Hazards, vol. 11, no. 3, pp. 283-303, 1995.

[5] A. K. Mishra and V. P. Singh, "Changes in extreme precipitation in Texas," Journal of Geophysical Research: Atmospheres, vol. 115, no. 14, Article ID D14106, 2010.

[6] C. Li, V. P. Singh, and A. K. Mishra, "Simulation of the entire range of daily precipitation using a hybrid probability distribution," Water Resources Research, vol. 48, no. 3, article 3521, 2012.

[7] P. Y. Groisman, R. W. Knight, D. R. Easterling, T. R. Karl, G. C. Hegerl, and V. N. Razuvaev, "Trends in intense precipitation in the climate record," Journal of Climate, vol. 18, no. 9, pp. 13261350, 2005.

[8] P. Zhai, X. Zhang, H. Wan, and X. Pan, "Trends in total precipitation and frequency of daily precipitation extremes over China," Journal of Climate, vol. 18, no. 7, pp. 1096-1108, 2005.

[9] I. R. Simpson and P. D. Jones, "Analysis of UK precipitation extremes derived from Met Office gridded data," International Journal of Climatology, vol. 34, no. 7, pp. 2438-2449, 2014.

[10] N. Qin, J. Wang, G. Yang, X. Chen, H. Liang, and J. Zhang, "Spatial and temporal variations of extreme precipitation and temperature events for the Southwest China in 1960-2009," Geoenvironmental Disasters, vol. 2, article 4, 2015.

[11] W. Choi, R. Tareghian, J. Choi, and C.-S. Hwang, "Geographically heterogeneous temporal trends of extreme precipitation in Wisconsin, USA during 1950-2006," International Journal of Climatology, vol. 34, no. 9, pp. 2841-2852, 2014.

[12] E. J. Powell and B. D. Keim, "Trends in daily temperature and precipitation extremes for the southeastern United States: 19482012," Journal of Climate, vol. 28, no. 4, pp. 1592-1612, 2015.

[13] J. Martin-Vide, "Spatial distribution of a daily precipitation concentration index in peninsular Spain," International Journal of Climatology, vol. 24, no. 8, pp. 959-971, 2004. 
[14] J. Abolverdi, G. Ferdosifar, D. Khalili, and A. A. KamgarHaghighi, "Spatial and temporal changes of precipitation concentration in Fars province, southwestern Iran," Meteorology and Atmospheric Physics, vol. 128, no. 2, pp. 181-196, 2016.

[15] M. H. I. Dore, "Climate change and changes in global precipitation patterns: what do we know?" Environment International, vol. 31, no. 8, pp. 1167-1181, 2005.

[16] M. Beniston and D. B. Stephenson, "Extreme climatic events and their evolution under changing climatic conditions," Global and Planetary Change, vol. 44, no. 1-4, pp. 1-9, 2004.

[17] D. Founda, K. H. Papadopoulos, M. Petrakis, C. Giannakopoulos, and P. Good, "Analysis of mean, maximum, and minimum temperature in Athens from 1897 to 2001 with emphasis on the last decade: trends, warm events, and cold events," Global and Planetary Change, vol. 44, no. 1-4, pp. 27-38, 2004.

[18] Q. Zhang, V. P. Singh, J. Li, F. Jiang, and Y. Bai, "Spatio-temporal variations of precipitation extremes in Xinjiang, China," Journal of Hydrology, vol. 434-435, no. 2, pp. 7-18, 2012.

[19] E. Yeşilırmak and L. Atatanır, "Spatiotemporal variability of precipitation concentration in western Turkey," Natural Hazards, vol. 81, no. 1, pp. 687-704, 2016.

[20] X. Li, F. Jiang, L. Li, and G. Wang, "Spatial and temporal variability of precipitation concentration index, concentration degree and concentration period Xinjiang, China," International Journal of Climatology, vol. 31, no. 11, pp. 1679-1693, 2011.

[21] R. Coscarelli and T. Caloiero, "Analysis of daily and monthly rainfall concentration in Southern Italy (Calabria region)," Journal of Hydrology, vol. 416-417, pp. 145-156, 2012.

[22] T. Caloiero, "Analysis of daily rainfall concentration in New Zealand," Natural Hazards, vol. 72, no. 2, pp. 389-404, 2014.

[23] P. Y. Groisman, T. R. Karl, D. R. Easterling et al., "Changes in the probability of heavy precipitation: important indicators of climatic change," Climatic Change, vol. 42, no. 1, pp. 243-283, 1999.

[24] J. Huang, S. Sun, and J. Zhang, "Detection of trends in precipitation during 1960-2008 in Jiangxi province, southeast China," Theoretical and Applied Climatology, vol. 114, no. 1-2, pp. 237-251, 2013.

[25] B. Alijani, J. O’Brien, and B. Yarnal, "Spatial analysis of precipitation intensity and concentration in Iran," Theoretical and Applied Climatology, vol. 94, no. 1-2, pp. 107-124, 2008.

[26] N. Cortesi, J. C. Gonzalez-Hidalgo, M. Brunetti, and J. Martin-Vide, "Daily precipitation concentration across Europe 1971-2010," Natural Hazards and Earth System Sciences, vol. 12, no. 9, pp. 2799-2810, 2012.

[27] P. Shi, X. Qiao, X. Chen et al., "Spatial distribution and temporal trends in daily and monthly precipitation concentration indices in the upper reaches of the Huai River, China," Stochastic Environmental Research and Risk Assessment, vol. 28, no. 2, pp. 201-212, 2014.

[28] W. Wang, W. Xing, T. Yang et al., "Characterizing the changing behaviours of precipitation concentration in the Yangtze River Basin, China," Hydrological Processes, vol. 27, no. 24, pp. 33753393, 2013.

[29] Q. Zhang, C.-y. Xu, M. Gemmer, Y. D. Chen, and C. Liu, "Changing properties of precipitation concentration in the Pearl River basin, China," Stochastic Environmental Research and Risk Assessment, vol. 23, no. 3, pp. 377-385, 2009.

[30] L. J. Zhang and Y. P. Qian, "Annual distribution features of precipitation in China and their interannual variations," Journal of Meteorological Research, vol. 17, no. 2, pp. 146-163, 2003.
[31] S. Feng, Q. Hu, and W. H. Qian, "Quality control of daily meteorological data in China, 1951-2000: a new dataset," International Journal of Climatology, vol. 24, no. 7, pp. 853-870, 2004.

[32] Y. Ding, Z. Wang, and Y. Sun, "Inter-decadal variation of the summer precipitation in East China and its association with decreasing Asian summer monsoon. Part I: observed evidences," International Journal of Climatology, vol. 28, no. 9, pp. 1139-1161, 2008.

[33] F. Jiang, X. Li, B. Wei, R. Hu, and Z. Li, "Observed trends of heating and cooling degree-days in Xinjiang Province, China," Theoretical and Applied Climatology, vol. 97, no. 3-4, pp. 349360, 2009.

[34] A. Agarwal, M. S. Babel, and S. Maskey, "Analysis of future precipitation in the Koshi river basin, Nepal," Journal of Hydrology, vol. 513, pp. 422-434, 2014.

[35] M. Almazroui, M. N. Islam, R. Dambul, and P. D. Jones, “Trends of temperature extremes in Saudi Arabia," International Journal of Climatology, vol. 34, no. 3, pp. 808-826, 2014.

[36] C. Qian, "On trend estimation and significance testing for non-Gaussian and serially dependent data: quantifying the urbanization effect on trends in hot extremes in the megacity of Shanghai," Climate Dynamics, vol. 47, no. 1-2, pp. 329-344, 2016.

[37] R. Wang and C. Li, "Spatiotemporal analysis of precipitation trends during 1961-2010 in Hubei province, central China," Theoretical and Applied Climatology, vol. 124, no. 1-2, pp. 385399, 2016.

[38] J. Huang, S. Sun, Y. Xue, and J. Zhang, "Spatial and temporal variability of precipitation indices during 1961-2010 in Hunan Province, central south China," Theoretical and Applied Climatology, vol. 118, no. 3, pp. 581-595, 2014.

[39] T. C. Peterson, D. R. Easterling, T. R. Karl et al., "Homogeneity adjustments of in situ atmospheric climate data: a review," International Journal of Climatology, vol. 18, no. 13, pp. 14931517, 1998.

[40] J. P. Li and Q. C. Zeng, "A new monsoon index, its interannual variability and relation with monsoon precipitation," Climatic and Environmental Research, vol. 10, no. 3, pp. 351-365, 2005 (Chinese).

[41] J. Li and Q. Zeng, "A new monsoon index and the geographical distribution of the global monsoons," Advances in Atmospheric Sciences, vol. 20, no. 2, pp. 299-302, 2003.

[42] H. Riehl, "Some aspects of Hawaiian rainfall," Bulletin of the American Mathematical Society, vol. 6, no. 5, pp. 176-177, 1949.

[43] M. J. Olascoaga, "Some aspects of Argentine Rainfall," Tellus, vol. 2, no. 4, pp. 312-318, 1950.

[44] R. Ananthakrishnan and M. K. Soman, "Statistical distribution of daily rainfall and its association with the coefficient of variation of rainfall series," International Journal of Climatology, vol. 9, no. 5, pp. 485-500, 1989.

[45] I. T. Jolliffe and P. B. Hope, "Representation of daily rainfall distributions using normalized rainfall curves," International Journal of Climatology, vol. 16, no. 10, pp. 1157-1163, 1996.

[46] Y. He, X. Mu, P. Gao et al., "Spatial variability and periodicity of precipitation in the middle reaches of the yellow river, China," Advances in Meteorology, vol. 2016, Article ID 9451614, 9 pages, 2016.

[47] P. Jiang, D. Wang, and Y. Cao, "Spatiotemporal characteristics of precipitation concentration and their possible links to urban extent in China," Theoretical and Applied Climatology, vol. 123, no. 3-4, pp. 757-768, 2016. 
[48] R. Monjo and J. Martin-Vide, "Daily precipitation concentration around the world according to several indices," International Journal of Climatology, vol. 36, no. 11, pp. 3828-3838, 2016.

[49] W. Shi, X. Yu, W. Liao, Y. Wang, and B. Jia, "Spatial and temporal variability of daily precipitation concentration in the Lancang River basin, China," Journal of Hydrology, vol. 495, pp. 197-207, 2013.

[50] V. P. Singh and L. Zhang, "Bivariate flood frequency analysis using the Copula method," Journal of Hydrologic Engineering, vol. 11, no. 2, pp. 150-164, 2006.

[51] M. Kendall, Rank Correlation Methods, Griffin, London, UK, 1975.

[52] H. B. Mann, "Nonparametric tests against trend," Econometrica, vol. 13, pp. 245-259, 1945.

[53] D. H. Burn and M. A. H. Elnur, "Detection of hydrologic trends and variability," Journal of Hydrology, vol. 255, no. 1-4, pp. 107122, 2002.

[54] E. Kahya and S. Kalayc1, "Trend analysis of streamflow in Turkey," Journal of Hydrology, vol. 289, pp. 128-144, 2004.

[55] Y. N. Chen and Z. X. Xu, "Plausible impact of global climate change on water resources in the Tarim River Basin," Science China Earth Sciences, vol. 48, no. 1, pp. 65-73, 2005.

[56] D. Liu, X. Chen, Y. Lian, and Z. Lou, "Impacts of climate change and human activities on surface runoff in the Dongjiang River basin of China," Hydrological Processes, vol. 24, no. 11, pp. 14871495, 2010.

[57] S. Yue, P. Pilon, B. Phinney, and G. Cavadias, "The influence of autocorrelation on the ability to detect trend in hydrological series," Hydrological Processes, vol. 16, no. 9, pp. 1807-1829, 2002.

[58] Y. Huang, W. H. Xiao, and L. H. Chen, "Analysis of temperature and precipitation characteristics in longtan reservoir basin during 1959-2014," Water Power, vol. 43, no. 2, pp. 18-22, 2017 (Chinese).

[59] D. R. Easterling, G. A. Meehl, C. Parmesan, S. A. Changnon, T. R. Karl, and L. O. Mearns, "Climate extremes: observations, modeling, and impacts," Science, vol. 289, no. 5487, pp. 20682074, 2000 .

[60] T. R. Karl and K. E. Trenberth, "Modern global climate change," Science, vol. 302, no. 5651, pp. 1719-1723, 2003.

[61] A. N. Nunes and L. Lourenço, "Precipitation variability in Portugal from 1960-2011," Journal of Geographical Sciences, vol. 25, no. 7, pp. 784-800, 2015.

[62] M. J. Zhang, J. Y. He, B. L. Wang et al., "Extreme drought changes in Southwest China from 1960 to 2009," Journal of Geographical Sciences, vol. 23, no. 1, pp. 3-16, 2013.

[63] D. Barriopedro, C. M. Gouveia, R. M. Trigo, and L. Wang, "The 2009/10 drought in China: Possible causes and impacts on vegetation," Journal of Hydrometeorology, vol. 13, no. 4, pp. 12511267, 2012.

[64] Y. H. Li, H. M. Xu, and D. Liu, "Features of the extremely severe drought in the east of southwest china and anomalies of atmospheric circulation in summer 2006," Journal of Meteorological Research, vol. 25, no. 2, pp. 176-187, 2011.

[65] L. Tan, Y. Cai, Z. An et al., "Decreasing monsoon precipitation in southwest China during the last 240 years associated with the warming of tropical ocean," Climate Dynamics, vol. 48, no. 5-6, pp. 1769-1778, 2017.

[66] T. Fischer, M. Gemmer, L. Liu, and B. Su, "Change-points in climate extremes in the Zhujiang River Basin, South China, 1961-2007," Climatic Change, vol. 110, no. 3-4, pp. 783-799, 2012. 

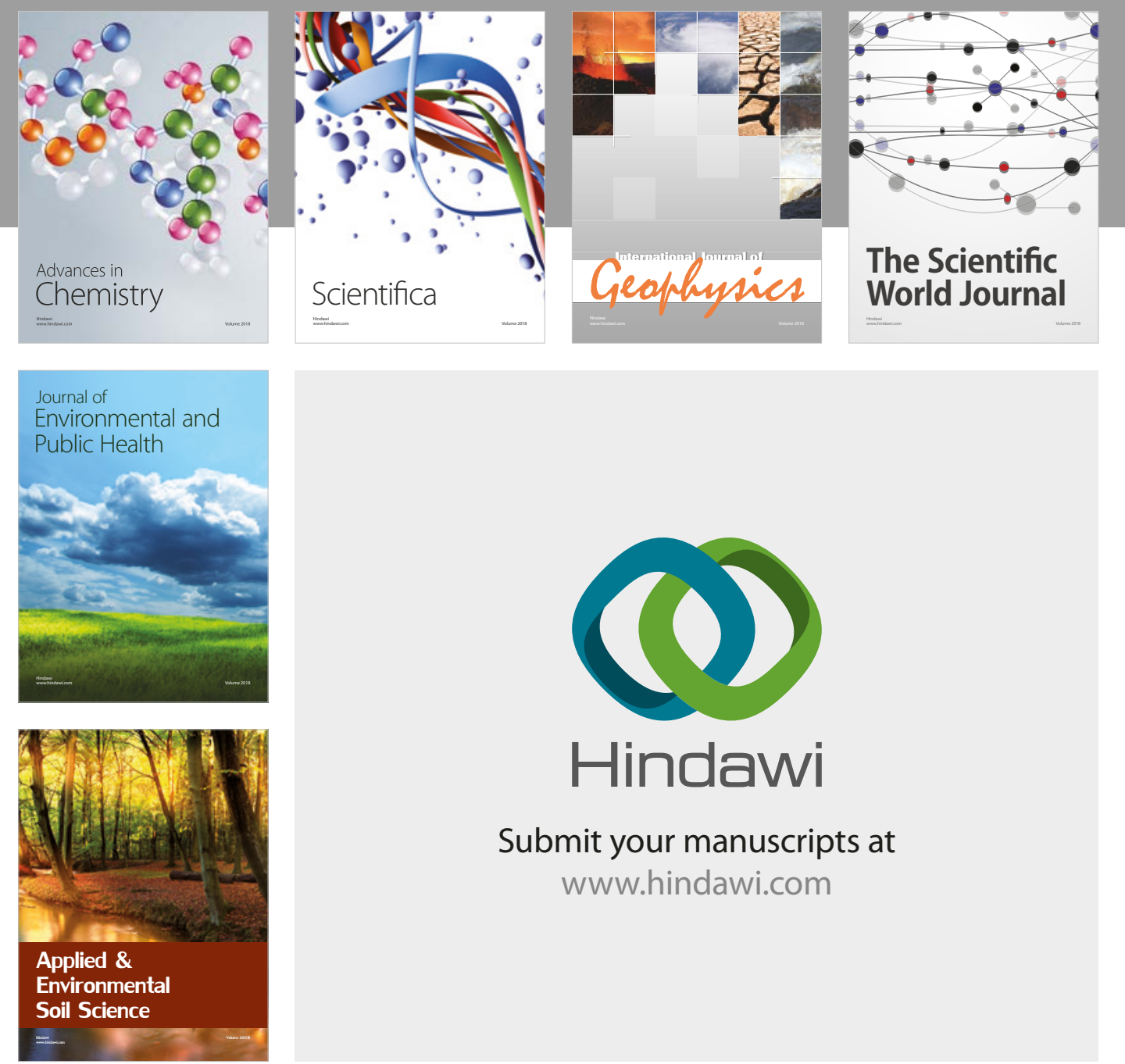

The Scientific

\section{World Journal}
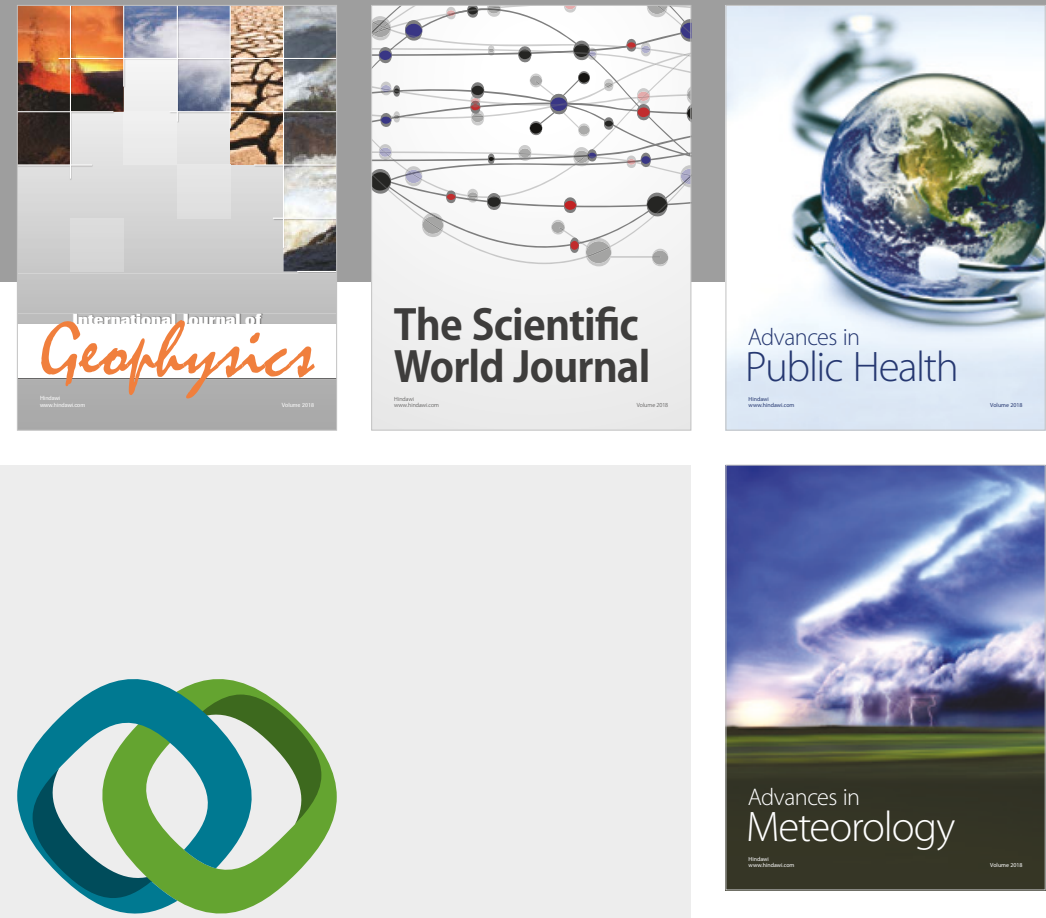

Advan

Public Health

\section{Hindawi}

Submit your manuscripts at

www.hindawi.com
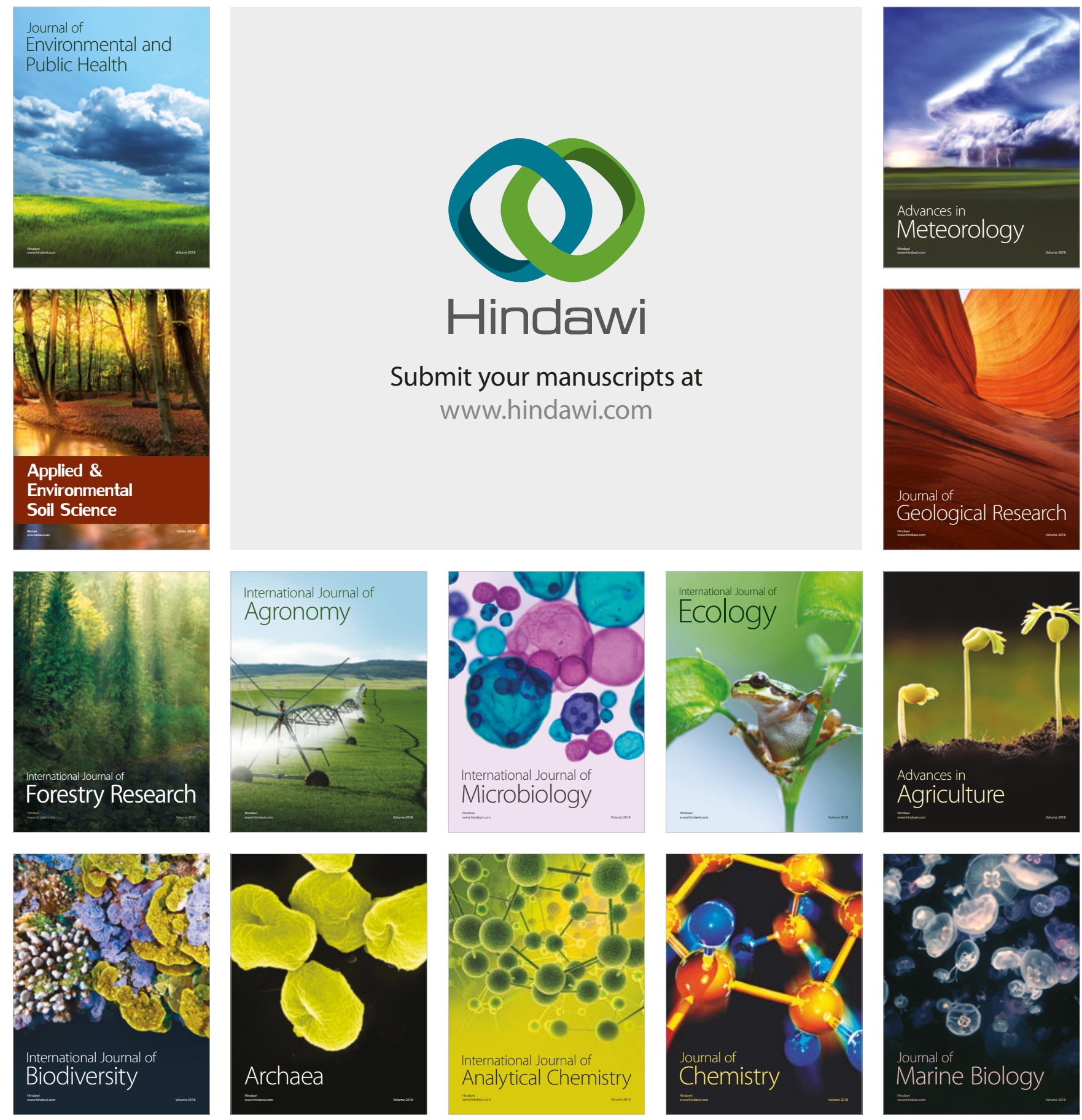